\title{
Identification of immune genes and proteins involved in the response of bovine mammary tissue to Staphylococcus aureus infection
}

\author{
Ylva C Strandberg Lutzow ${ }^{1,2}$, Laurelea Donaldson 1,2, Christian P Gray 1,2,4, \\ Tony Vuocolo ${ }^{1,2}$, Roger D Pearson ${ }^{1}$, Antonio Reverter ${ }^{1}$, Keren A Byrne ${ }^{1,2}$, \\ Paul A Sheehy ${ }^{1,3}$, Ross Windon ${ }^{5}$ and Ross L Tellam*1,2
}

\begin{abstract}
Address: ${ }^{1}$ Co-operative Research Centre for Innovative Dairy Products, Australia, ${ }^{2}$ CSIRO Livestock Industries, Queensland Bioscience Precinct, 306 Carmody Rd, St Lucia, QLD 4067, Australia, ${ }^{3}$ Centre for Advanced Technologies in Animal Genetics and Reproduction (REPROGEN), Faculty of Veterinary Science, University of Sydney, Sydney, 2006, NSW, Australia, ${ }^{4}$ School of Veterinary Science, The University of Queensland, Brisbane, 4072, Australia and ${ }^{5}$ CSIRO Livestock industries, FD McMaster laboratory, Chiswick, Armidale, NSW, 2350, Australia

Email: Ylva C Strandberg Lutzow - ylva.strandberg@csiro.au; Laurelea Donaldson - laddon@westnet.com.au;

Christian P Gray - c.gray@uq.edu.au; Tony Vuocolo - tony.vuocolo@csiro.au; Roger D Pearson - roger.pearson@csiro.au; Antonio Reverter - toni.reverter-gomez@csiro.au; Keren A Byrne - keren.byrne@csiro.au; Paul A Sheehy - psheehy@vetsci.usyd.edu.au; Ross Windon - ross.windon@csiro.au; Ross L Tellam* - ross.tellam@csiro.au

* Corresponding author
\end{abstract}

Published: 2 June 2008

BMC Veterinary Research 2008, 4:18 doi:10.1186/1746-6/48-4-18

This article is available from: http://www.biomedcentral.com/1746-6/48/4/18

(c) 2008 Lutzow et al; licensee BioMed Central Ltd.

This is an Open Access article distributed under the terms of the Creative Commons Attribution License (http://creativecommons.org/licenses/by/2.0), which permits unrestricted use, distribution, and reproduction in any medium, provided the original work is properly cited.

\begin{abstract}
Background: Mastitis in dairy cattle results from infection of mammary tissue by a range of microorganisms but principally coliform bacteria and Gram positive bacteria such as Staphylococcus aureus. The former species are often acquired by environmental contamination while $S$. aureus is particularly problematic due to its resistance to antibiotic treatments and ability to reside within mammary tissue in a chronic, subclinical state. The transcriptional responses within bovine mammary epithelial tissue subjected to intramammary challenge with $S$. aureus are poorly characterised, particularly at the earliest stages of infection. Moreover, the effect of infection on the presence of bioactive innate immune proteins in milk is also unclear. The nature of these responses may determine the susceptibility of the tissue and its ability to resolve the infection.

Results: Transcriptional profiling was employed to measure changes in gene expression occurring in bovine mammary tissues sampled from three dairy cows after brief and graded intramammary challenges with $S$. aureus. These limited challenges had no significant effect on the expression pattern of the gene encoding $\beta$-casein but caused coordinated up-regulation of a number of cytokines and chemokines involved in pro-inflammatory responses. In addition, the enhanced expression of two genes, SI00 calcium-binding protein AI2 (SI00A/2) and Pentraxin-3 (PTX3) corresponded with significantly increased levels of their proteins in milk from infected udders. Both genes were shown to be expressed by mammary epithelial cells grown in culture after stimulation with lipopolysaccharide. There was also a strong correlation between somatic cell count, a widely used measure of mastitis, and the level of SIO0AI2 in milk from a herd of dairy cows. Recombinant SIO0A 12 inhibited growth of Escherichia coli in vitro and recombinant PTX3 bound to E. coli as well as $\mathrm{Clq}$, a subunit of the first component of the complement cascade.
\end{abstract}




\begin{abstract}
Conclusion: The transcriptional responses in infected bovine mammary tissue, even at low doses of bacteria and short periods of infection, probably reflect the combined contributions of gene expression changes resulting from the activation of mammary epithelial cells and infiltrating immune cells. The secretion of a number of proinflammatory cytokines and chemokines from mammary epithelial cells stimulated by the bacteria serves to trigger the recruitment and activation of neutrophils in mammary tissue. The presence of SIO0AI2 and PTX3 in milk from infected udder quarters may increase the anti-bacterial properties of milk thereby helping to resolve the mammary tissue infection as well as potentially contributing to the maturation of the newborn calf epithelium and establishment of the newborn gut microbial population.
\end{abstract}

\section{Background}

Mastitis in dairy cattle continues to be an economically important disease. Despite extensive management practices including antibiotic treatments, mastitis is estimated to cause annual losses in excess of two billion dollars per annum in the United States alone [1,2]. These losses arise from reduction in milk yield, waste of milk unfit for consumption, antibiotic use and premature culling. The disease can be caused by a wide range of Gram negative coliform and Gram positive bacteria, as well as yeast, fungi and mycoplasma. However, contagious mastitis, which is transmitted from cow to cow during milking, is principally caused by Staphylococcus aureus [3]. Unlike many other major mastitis-causing pathogens, which are generally associated with acute infections acquired from environmental reservoirs of bacteria, $S$. aureus causes chronic subclinical infections. Control is complicated by a high prevalence of resistance to antibiotics [4]. The ability of this bacterium to live within some cells and encapsulated nodules in mammary tissue may contribute to its resistance to antibiotic treatments [5-7].

The innate immune system in mammals is one of the first lines of host defense to infection as it has the capacity to immediately recognise and respond to the earliest signs of infection. Both acute and chronic mastitis conditions are associated with a dramatic increase in somatic cell count (SCC) in milk, with neutrophils being the predominant leukocyte found in both the infected mammary quarter and milk $[8,9]$. Neutrophils are essential cellular components of the innate immune system [10] and their accumulation and activation at the site of infection requires local induction of a panel of innate immune molecules, including various chemokines and cytokines [11]. Early innate immune responses also occur in mammary epithelial cells and these responses underpin subsequent neutrophil infiltration into mammary tissue, the activation of these innate immune cells and increases in milk SCC [12$14]$.

Several studies have examined gene expression in circulating leukocytes close to parturition, a time when cows are more susceptible to mastitis infection, as well as during acute mastitis infections $[10,15,16]$. These studies and others using mammary tissue demonstrated that expression of a number of genes involved in immune cell activation, chemotaxis and apoptosis was altered $[11,17,18]$. Moreover, these gene expression changes have often been shown to translate into corresponding protein expression alterations thereby demonstrating that transcriptional mechanisms primarily control the innate immune response [19-21]. The majority of these studies used infection models that resulted in very strong mammary tissue responses, or measured the responses relatively late after experimental inoculation or during acute naturally acquired clinical mastitis when significant necrotic damage may have been evident.

Recent studies have begun to elucidate the direct role of mammary epithelial cells (MEC) in the stimulation of the innate immune response $[12,14,22]$. These studies indicate that MEC respond robustly and rapidly to challenge by either low levels of bacteria or bacterial cell wall components with marked changes in expression of proinflammatory cytokines and chemokines [23]. This response probably underpins the subsequent infiltration of mammary tissues by immune cells, particularly neutrophils $[8,9]$. A broader and more comprehensive examination of gene expression changes produced in mammary epithelial cells and infiltrating immune cells in response to mammary tissue infection with $S$. aureus may identify the network of gene expression changes that coordinates the early innate immune responses of this tissue. Of particular interest are the local mammary tissue responses after initial infection with low numbers of bacteria before the onset of widespread tissue damage.

Microarray technology has become an important tool to address complex biological questions by simultaneously measuring the expression of thousands of genes within a tissue. Identification of patterns of gene expression can provide insight into the biological functions of their encoded proteins and the networks of protein interactions governing responses of cells to extracellular stimuli. One aim of the current study was to identify the network of genes that becomes activated in mammary tissue in 
response to a brief and graded intramammary challenge with $S$. aureus. The identification of these poorly characterised genes and in-depth characterisation of their corresponding proteins may be important for the development of novel strategies to enhance resistance of cows to mastitis and the development of novel antibacterial therapeutic agents. The consequences of these responses in terms of potential secretion of bioactive innate immune proteins into milk may also have relevance to the suckling calf. Thus, a second aim is to characterise the biological activities of innate immune proteins that may be present in milk from infected udder quarters.

\section{Results}

\section{S. aureus challenge of bovine mammary tissue}

To ensure that the dairy cows used in the experiment were free from bacterial infection, milk samples were taken from each udder quarter $24 \mathrm{~h}$ and $48 \mathrm{~h}$ prior to intramammary $S$. aureus infusions and tested for bacterial growth. All quarters from two cows and three quarters from a third cow showed no bacterial growth. Milk from one quarter of one cow (1419) showed low level growth of S. aureus 24 $\mathrm{h}$ prior to the commencement of the experiment, presumably from a mild field mastitis infection. Consequently, this quarter was excluded from the experiment. One quarter of each cow was treated with pyrogen-free PBS and this quarter acted as the intra-animal control for subsequent analyses. Each cow received different graded doses of $S$. aureus (strain JG80) by intramammary infusion, ranging from $5 \times 10^{2}$ to $1 \times 10^{6}$ bacteria (Table 1 ).

Milk samples were also taken from each quarter $16 \mathrm{~h}$ after $S$. aureus experimental infusion and tested for bacterial growth. The bacterial culture was identified and tested for hemolysis, catalase and coagulase activities (Table 2). All milk samples from the quarters experimentally infused with $S$. aureus contained bacteria with positive catalase and coagulase activities and at least partial hemolysis activity on blood agar plates. The bacteria in all of these samples were identified as $S$. aureus. The milk samples from quarters infused with pyrogen-free PBS had no $S$. aureus growth, which was consistent with the view that each quarter within an udder is a semi-autonomous physiological unit and can be considered an independent experimental unit during this relatively brief experimental bacterial challenge [24-26].

Table I: Dose of S. aureus (bacteria/5 $\mathrm{ml}$ ) given by intramammary infusion into each udder quarter

\begin{tabular}{ccccc}
\hline Cow & Left Fore & Right Fore & Left Hind & Right Hind \\
\hline 1490 & PBS & $5 \times 10^{2}$ & $1 \times 10^{4}$ & $1 \times 10^{5}$ \\
1592 & $1 \times 10^{4}$ & PBS & $1 \times 10^{5}$ & $1 \times 10^{6}$ \\
1419 & PBS & nil' & $1 \times 10^{5}$ & $1 \times 10^{6}$ \\
\hline
\end{tabular}

I This quarter was not used
Quantitative RT-PCR (qRT-PCR) was used to measure the expression patterns of selected genes in mammary tissue samples taken from each animal $16 \mathrm{~h}$ after the $S$. aureus infusion (Fig. 1). There were no significant changes in the expression levels of $\alpha$-S1-casein (CSN1S1) or $\beta$-casein (CSN2) as a function of bacterial dose compared with each intra-animal control sample $(P>0.05)$ for all three cows (Fig. 1(a)). Therefore, the relatively low doses of $S$. aureus in combination with the relatively brief infection period did not affect the expression of these milk protein genes in any quarter. This indicates that the experimental model was a good representation of the early stages of infection before there was significant tissue damage leading to the suppression of normal physiological functions.

The expression patterns of the pro-inflammatory cytokines tumor necrosis factor alpha (TNF $\alpha)$, interleukin 1 beta $(I L-1 \beta)$, interleukin $8(I L-8)$, interleukin $6(I L-6)$ and CD14 antigen (CD14), a pivotal cell surface protein mediating detection of bacterial cell wall components, were measured as representatives of early response innate immune genes that are typically up-regulated by bacterial infections of mammary tissue $[12,14,27]$. For each of these genes, and within each cow, there were strong and significant responses to the highest bacterial doses compared with each intra-animal control $(P<0.01)$ (Fig. 1 (b)). Moreover, the responses were dose-dependent, or at least partially so. However, the magnitudes of the foldchanges in gene expression were variable across the three cows for each gene. For example, at a dose of $1 \times 10^{5} \mathrm{bac}-$ teria, the fold changes for TNF $\alpha$ were 39.8 (cow 1419), 26.2 (cow 1490) and 7.8 (cow 1592) (all P<0.01). Furthermore, the responses of samples from cow 1419 for all of the measured pro-inflammatory cytokines were more pronounced than the responses in the two other cows. For $I L-8$ the fold changes were much greater compared with TNF $\alpha$ and also more pronounced in cow 1419. The fold changes for $I L-8$ were 603 and 2835 at the bacterial doses of $1 \times 10^{5}$ and $1 \times 10^{6}$, respectively for cow 1419 , while corresponding figures for cow 1592 were 122 and 75 fold (all $\mathrm{P}<0.01$ ).

\section{Microarray analyses of mammary tissue challenged with different doses of $S$. aureus}

We used the Bovine Innate Immune Microarray [28] to identify a more complete repertoire of differentially expressed transcripts in bovine udder tissues from the three dairy cows challenged by intramammary infusion with $S$. aureus. It was clear from the cow to cow variations in the initial gene expression data that each cow required independent assessment (Fig. 1(b)). Consequently, an 'All-Pairs' experimental design was used for each cow i.e. each sample taken from one cow was tested against all other samples from the same cow with each comparison also involving dye swaps (Fig. 2). In this manner, every 
Table 2: Pathology of milk samples $16 \mathrm{~h}$ post-infusion

\begin{tabular}{|c|c|c|c|c|c|}
\hline Cow & Test & Left Fore & Right Fore & Left Hind & Right Hind \\
\hline \multirow[t]{7}{*}{ \#1490 } & Dose ${ }^{1}$ & PBS & $5 \times 10^{2}$ & $1 \times 10^{4}$ & $1 \times 10^{5}$ \\
\hline & Growth ${ }^{2}$ & Minor ${ }^{8}$ & + & + & + \\
\hline & Gramstain $^{3}$ & - & + & + & + \\
\hline & Hemolysis ${ }^{4}$ & - & partial & partial & + \\
\hline & Catalase $^{5}$ & - & + & + & + \\
\hline & Coagulase $^{6}$ & - & + & + & + \\
\hline & Isolate 7 & n.d. & S. aureus & S. aureus & S. aureus \\
\hline \multirow[t]{7}{*}{ \#1592 } & Dose & $1 \times 10^{4}$ & PBS & $1 \times 10^{5}$ & $1 \times 10^{6}$ \\
\hline & Growth & + & none & + & + \\
\hline & Gramstain & + & - & + & + \\
\hline & Hemolysis & partial & - & partial & partial \\
\hline & Catalase & + & - & + & + \\
\hline & Coagulase & + & - & + & + \\
\hline & Isolate & S. aureus & none & S. aureus & S. aureus \\
\hline \multirow[t]{7}{*}{ \#1419 } & Dose & PBS & Nil & $1 \times 10^{5}$ & $1 \times 10^{6}$ \\
\hline & Growth & none & + & + & + \\
\hline & Gramstain & - & + & + & + \\
\hline & Hemolysis & - & partial & partial & partial \\
\hline & Catalase & - & + & + & + \\
\hline & Coagulase & - & + & + & + \\
\hline & Isolate & none & S. aureus & S. aureus & S. aureus \\
\hline
\end{tabular}

I Bacterial dose

2 Bacterial growth (+/-)

3 Gram positive or Gram negative

4 Hemolysis; hemolytic on blood agar (+, partial, -)

5 Catalase $(+/-)$

${ }^{6}$ Coagulase (+/-)

${ }^{7}$ Bacterial species identified

8 Minor bacterial growth was observed but this was not $S$. aureus.

sample was measured a total of six times, which allowed identification of differentially expressed genes with respect to the intra-animal control with a False Discovery Rate (FDR) adjusted $\mathrm{P}<0.05$ [29]. Differentially expressed elements were independently identified for each cow. In a conservative extension of this analysis, a subset of the significantly differentially expressed elements was selected that had: (i) expression data in all test samples and; (ii) showed at least 2-fold change in expression in any of the test samples compared to the control sample. The signal for each of these 183 differentially expressed elements was then averaged in all cows receiving the same dose. In this way, gene expression values were obtained for these genes from the test quarters infused with $S$. aureus at dose rates of $500(n=1), 10,000$ $(n=2), 100,000(n=3)$ or 1,000,000 $(n=2)$ bacteria relative to the control quarters. The expression data for these 183 elements were clustered using a K-means algorithm into 9 clusters using default parameters [30]. The gene redundancy on the microarray revealed overlap between several of the clusters. Consequently, these clusters were manually collapsed into two primary clusters in which the significantly differentially expressed elements were either reduced (repressed) or increased (induced) in response to S. aureus infection (Fig. 3). Each cluster is represented by the centroid of gene expression for all elements in the cluster. The 128 elements that showed increased expression in response to $S$. aureus challenge are shown in Figure $3(\mathrm{a})$, while the 55 elements with decreased gene expression in response to S. aureus are presented in Figure 3(b).

The cluster containing elements that were up-regulated in response to infection showed increased gene expression only as the number of infused bacteria reached a threshold dose i.e. the centroid for this cluster showed little response at a dose up to 10,000 bacteria but a strong and sustained positive response at higher doses. As expected from the data, there was substantial variation in the responses of individual genes at the higher doses ( $\mathrm{cf}$ Fig. $1)$. The characteristics of this cluster are exemplified by the responses of genes such as $I L-6, I L-1 \beta$ and $I L-8$ (Fig. 1(b)). The cluster containing down-regulated genes showed sup- 


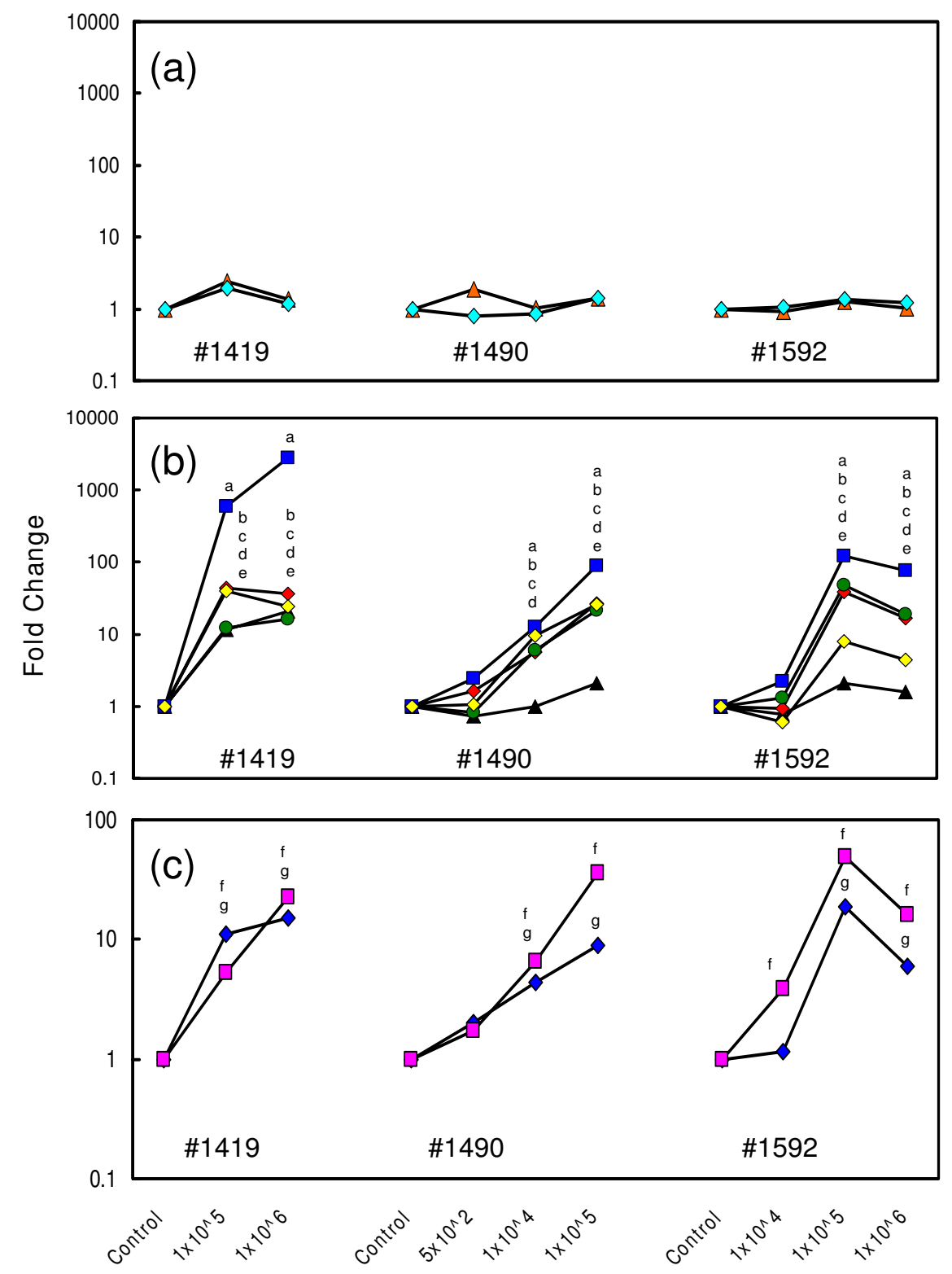

\section{Figure I}

Relative expression of selected genes in mammary tissue challenged with $\mathbf{S}$. aureus. The relative gene expression levels of selected genes were measured by qRT-PCR. Samples were obtained from mammary tissues of three Holstein Friesian cows at peak lactation 16 hours following intramammary infusion with increasing doses of $S$. aureus into the separate udder quarters. Data for each gene are expressed as relative fold changes compared to expression in the intra-animal control tissue for each animal. The genes tested included: (a) $\alpha$-SI-casein (CSNISI) (turquoise diamond) and $\beta$-casein (CSN2) (red triangle); (b) Interleukin 8 (IL-8a) (blue square), Interleukin I $\beta$ (IL-I $\left.\beta^{b}\right)$ (red diamond), Tumor necrosis factor $\alpha$ (TNF $\left.\alpha^{c}\right)$ (yellow diamond), Interleukin 6 (IL-6 ${ }^{d}$ ) (green circle) and CDI4 antigen (CD/4e) (black triangle); (c) SI 00 calcium-binding protein AI2 $\left(S / 00 A / 2^{f}\right)$ (blue diamond) and Pentraxin-3 (PTX3g) (pink square). Expression data for each gene were analysed by ANOVA. The superscript letters are specific for each gene tested and signify significant differences $(P<0.0 \mathrm{I})$ between a specific infection dose and the corresponding intramammary control for each cow. 


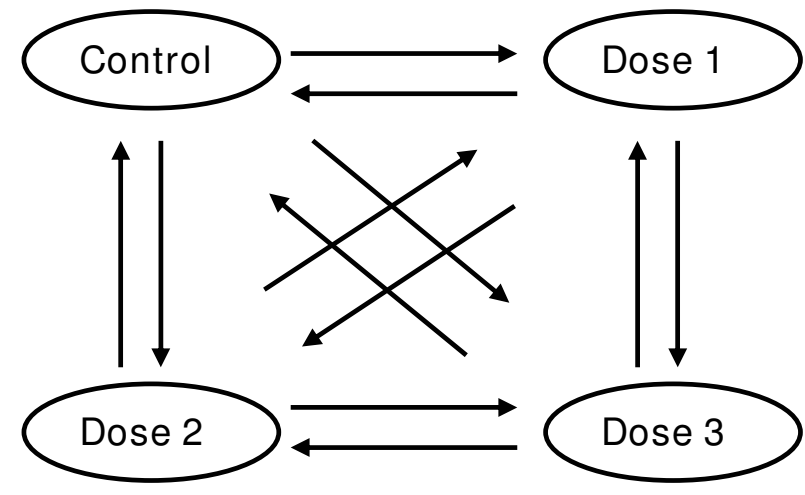

Figure 2

Microarray experimental design. Gene expression in mammary tissue samples from each cow was analysed by microarray hybridisation using an 'all-pairs design'. The figure is a schematic representation of the microarray design used for each cow (except cow 1419 which only had 2 intramammary bacterial infusions), where each arrow represents one microarray slide with the direction of the arrow indicating the cDNA labelling from Cy5 to Cy3-labelled cDNA.

pression of gene expression compared to the controls at all bacterial doses, although these effects were not as marked.

A number of the differentially expressed elements identified by this analysis were anonymous on the microarray and consequently inserts from the corresponding cDNA clones were sequenced and annotated. This process revealed that the 128 up-regulated elements represented 56 unique transcripts (Table 3) while the 55 down-regulated elements represented 42 unique transcripts (Table 4). This reflected the redundancy of elements on the microarray and the technical replication of the data. Due to the biased representation of innate immune genes on the microarray, a Gene Ontology (GO) analysis was not performed to identify enriched GO terms. For convenience of presentation and discussion however, the differentially expressed genes were placed in several functional categories, which were derived by direct examination of the scientific literature (Tables 3 and 4 ).

The up-regulated genes were dominated by 22 genes encoding proteins involved in intercellular signalling. Many of these were well defined pro-inflammatory cytokines and chemokines (eg. CXCL1, CXCL2, IFN $\gamma$, IL6 , IL- 8 and IL-1 $\beta$ ) as well as proteins with less defined functions but associated with inflammatory responses (eg. S100A12 and PTX3) [31,32]. Interestingly, this group of genes also included leptin $(L E P)$, alluding to a link between infection and energy partitioning in the form of lipid storage and metabolism [33]. Another group (10 genes) associated with the up-regulated genes was characterised as cell surface receptors. Many of these are intimately associated with the previous functional group. For example, the Toll-like receptor pathway senses and responds to bacterial infections through the Toll-like receptor signalling pathway resulting in stimulation of synthesis of a number of pro-inflammatory cytokines and chemokines [34]. This specific pathway is represented by toll-like receptor 2 (TLR2), toll-like receptor 4 (TLR4) and CD14 [35,36]. Both TLR2 and TLR4 are membranebound pattern recognition receptors. In addition, the cell surface receptor group contains TNF receptor superfamily 9 (TNFRSF9) and CD40 antigen (CD40), both of which are components of the TNF receptor superfamily. The upregulation of a group of transcription factors and transcriptional co-regulators ( 8 genes) may be underlying the transcriptional changes of other genes in these clusters. Many of these former genes encode proteins that are pivotal regulators of innate immune responsiveness e.g. FOS,

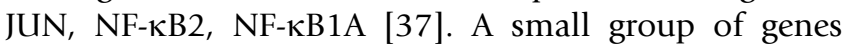
involved in apoptosis was also identified.

The cluster containing the down-regulated genes was dominated by 10 genes encoding proteins which are components of the cytoskeleton or extracellular matrix. Thus, even over the relatively short duration of the infection, the beginning of a tissue remodelling process may have been in progress, although this did not adversely affect the transcription of milk protein genes. Other major functional groups in this cluster included apoptosis (4 genes), cell surface receptors ( 7 genes) and intercellular signalling proteins ( 6 genes). The latter group encoded a diverse group of proteins including interleukin 13 (IL-13), which normally suppresses proinflammatory cytokine production [38,39]. Resistin (RETN), another member of this group, is an adipocyte-secreted protein involved in type II diabetes and obesity and its identification provides a further link between energy metabolism and inflammatory responses in mammary tissue $[40,41]$. Somewhat surprisingly, $C A M P$, which encodes a cathelicidin anti-microbial peptide, was also in this down-regulated group. Although the qRT-PCR data indicated no significant change in the expression of $\alpha \mathrm{S} 1$-casein (CSN1S1), the microarray data included this gene in the list of down-regulated genes. The reasons for this discrepancy are not clear but could reflect higher reproducibility of the microarray data relative to the qRT-PCR data for genes that are highly expressed.

Validation of differentially expressed genes using qRT-PCR All of the genes, with the exception of CD14 and TNF $\alpha$, that were differentially expressed as defined by the initial qRT-PCR analyses (Fig. 1(b)), were also differentially expressed when measured by microarray analysis. The reasons why CD14 and TNF $\alpha$ were not identified in the microarray analysis but showed differential expression 

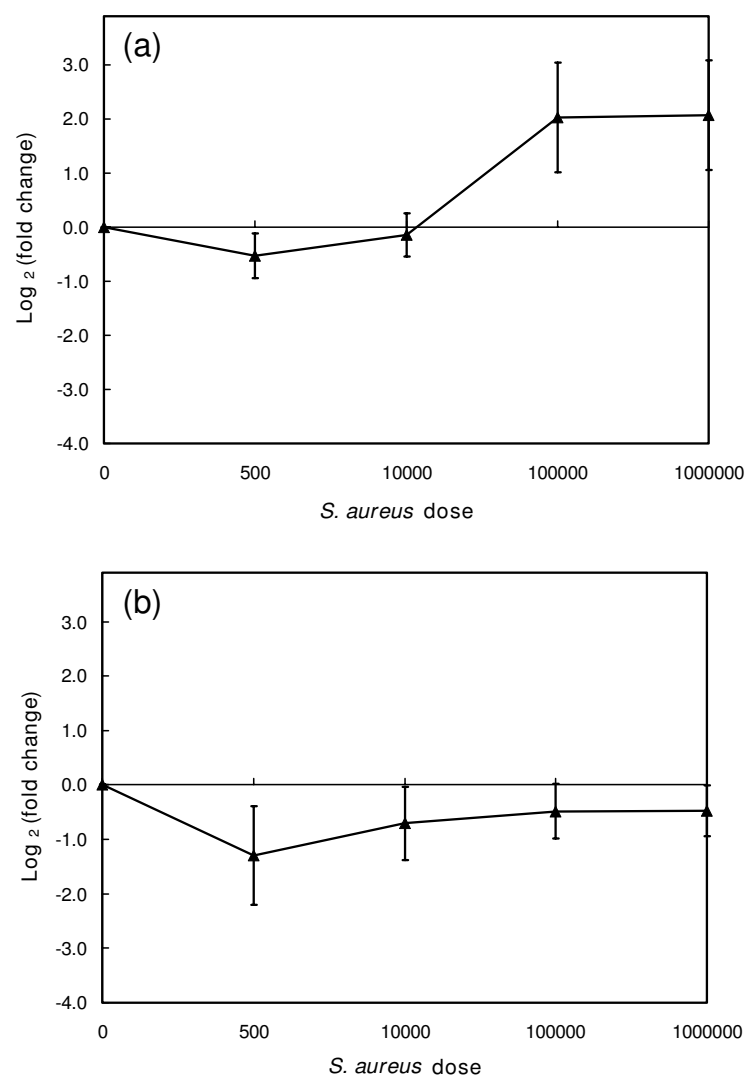

Figure 3

Clusters of differentially expressed genes in response to intramammary infusion of S. aureus. Microarrays were performed on tissue from each mammary quarter with data compared to the intramammary control for each cow to identify differentially expressed transcripts. The figure shows the mean gene expression cluster profiles for the significantly differentially expressed elements that were either up-regulated (a) or down-regulated (b) relative to the control in response to intramammary infusion of $S$. aureus. The clusters only contain significantly differentially expressed elements that were expressed in all samples and showed at least 2 fold change relative to the control in at least one sample. RNA samples were obtained from mammary tissue of three Holstein Friesian cows at peak lactation that had been infused with pyrogen-free PBS (dose $0, n=3$ ) in one quarter (intraanimal controls) and in other quarters with $S$. aureus at dose rates of $500(n=1), 10,000(n=2), 100,000(n=3)$ or $1,000,000(n=2)$ bacteria. Data are expressed as $\log _{2}$ (fold change) \pm I S.D. for the centroid of the cluster.

when measured by qRT-PCR are not clear but may relate to the conservative process used in the former analysis and the differing sensitivities of the two technologies. qRTPCR was also used to verify the differential expression of two additional up-regulated genes, S100A12 (S100 calcium-binding protein A12) and PTX3 (Pentraxin 3)), identified by the microarray analysis (Fig. 1(c)). Consistent with the general trends in previous data (Fig. 1(b)), the expression patterns of S100A12 and PTX3 were significantly up-regulated within each cow but showed varying responses relative to each intra-animal control. At the common infection dose of $1 \times 10^{5}$ bacteria for cows 1419, 1490 and 1592, there was 5.2, 36.5 and 49.1 fold up-regulation of S100A12 expression and 11.1, 9.9 and 19 fold up-regulation of PTX3 expression, compared to the intraanimal controls, respectively (all $\mathrm{P}<0.01$ ) (Fig. 1(c)).

\section{Expression of SIOOAI 2 and PTX3 after stimulation of bovine mammary epithelial cells with lipopolysaccharide or lipoteichoic acid}

The expression levels of S100A12 and PTX3 transcripts in primary bovine mammary epithelial cells (bMEC) grown in cell culture were significantly increased in response to stimulation by $50 \mu \mathrm{g} / \mathrm{ml}$ of lipopolysaccharide (LPS) or $20 \mu \mathrm{g} / \mathrm{ml}$ of lipoteichoic acid (LTA) for a period of $24 \mathrm{~h}$ (Fig. 4). S100A12 was significantly $(\mathrm{P}<0.01)$ up-regulated 4-24 $\mathrm{h}$ after LPS stimulation with a maximal fold change of 10.6 at $24 \mathrm{~h}$. The effect of stimulation with LTA was less pronounced and resulted in significantly ( $\mathrm{P}<$ 0.01 ) increased S100A12 mRNA expression at 8-24 h post-stimulation with the expression reaching a plateau at $16 \mathrm{~h}$ (Fig. 4(a)). PTX3 was up-regulated at $4 \mathrm{~h}$ (2.2 fold) of stimulation with LPS $(\mathrm{P}<0.01)$ but then declined to basal levels. LTA stimulation resulted in enhanced expression of PTX3 at $2 \mathrm{~h}$ post-stimulation $(4.5$ fold $)(\mathrm{P}<0.01)$ but the levels thereafter rapidly declined and at $16 \mathrm{~h}$ and $24 \mathrm{~h}$ there were significantly $(\mathrm{P}<0.01)$ lower levels of expression compared to the starting sample (Fig. 4(b)). Thus, bMEC were likely to be the origin of at least some of the enhanced expression of S100A12 and PTX3 observed in mammary tissue challenged with $S$. aureus. Moreover, the time course responses for S100A12 and PTX3 were strikingly different.

\section{Expression and purification of rSIOOAII2 and rPTX3}

The coding sequences for bovine S100A12 and the mature form of bovine PTX3 were amplified by PCR, sequence verified and cloned into the $\mathrm{PQE9}$ vector. The respective recombinant proteins, rS100A12 and rPTX3, were solubilised from inclusion bodies using $8 \mathrm{M}$ urea and purified using Ni-NTA affinity chromatography. SDS-polyacrylamide gel analyses confirmed that the purified protein monomers were of the predicted sizes, i.e. $\sim 11 \mathrm{kDa}$ for rS100A12 and $\sim 40 \mathrm{kDa}$ for rPTX3 (Fig. 5). The latter protein was reduced and alkylated before analysis as this was required to ensure removal of rPTX3 oligomers. N-terminal sequencing further validated the identities of the two recombinant proteins. These recombinant proteins were used to raise corresponding polyclonal antibodies in rab- 
Table 3: Significantly up-regulated genes in mammary tissue challenged with S. aureus.

\begin{tabular}{|c|c|c|c|}
\hline Function & Gene symbol & Genbank accession & Genbank description \\
\hline \multicolumn{4}{|c|}{ Chemokine, cytokine and intercellular signalling } \\
\hline & CCLII & NM 002986 & $\begin{array}{l}\text { Homo sapiens chemokine (C-C motif) ligand II } \\
\text { (CCLIII), mRNA }\end{array}$ \\
\hline & $C C L 2$ & NM 174006 & $\begin{array}{l}\text { Bos taurus chemokine (C-C motif) ligand } 2 \text { (CCL2), } \\
\text { mRNA. }\end{array}$ \\
\hline & CCL2O & NM 004591 & $\begin{array}{l}\text { Homo sapiens chemokine (C-C motif) ligand } 20 \\
\text { (CCL20), mRNA }\end{array}$ \\
\hline & CCL3LI & NM 021006 & $\begin{array}{l}\text { Homo sapiens chemokine (C-C motif) ligand 3-like I } \\
\text { (CCL3LI), mRNA }\end{array}$ \\
\hline & CCL4LI & AY575854 & $\begin{array}{l}\text { Homo sapiens similar to cytokine (LOC388372), } \\
\text { mRNA }\end{array}$ \\
\hline & CSF3 & NM 172219 & $\begin{array}{l}\text { Homo sapiens colony stimulating factor } 3 \\
\text { (granulocyte) (CSF3), transcript variant } 2, \text { mRNA }\end{array}$ \\
\hline & CXCLI & NM 001511 & $\begin{array}{l}\text { Homo sapiens chemokine (C-X-C motif) ligand I } \\
\text { (melanoma growth stimulating activity, }\end{array}$ \\
\hline & CXCL2 & NM 002089 & $\begin{array}{l}\text { Homo sapiens chemokine ( } \mathrm{C}-\mathrm{X}-\mathrm{C} \text { motif) ligand } 2 \\
\text { (CXCL2), mRNA }\end{array}$ \\
\hline & CXCLIO & $\underline{A B 070717}$ & $\begin{array}{l}\text { Homo sapiens chemokine (C-X-C motif) ligand } 10 \\
(C X C L I 0), \text { mRNA }\end{array}$ \\
\hline & ILIB & NM 174093 & Bos taurus interleukin I, beta (ILIB), mRNA. \\
\hline & IL6 & NM 001009392 & Ovis aries interleukin 6 (IL6), mRNA \\
\hline & IFNG & NM 174086 & $\begin{array}{l}\text { interferon-gamma; Bos taurus interferon, gamma or } \\
\text { immune type [interferon gamma type 2] }\end{array}$ \\
\hline & IL8 & NM 173925 & $\begin{array}{l}\text { Bos taurus interleukin } 8 \text { [neutrophil activating } \\
\text { peptide I] (IL8), mRNA. }\end{array}$ \\
\hline & LEP & NM 173928 & Bos taurus leptin [obesity] (LEP), mRNA \\
\hline & PLAUR & NM 174423.2 & $\begin{array}{l}\text { Homo sapiens plasminogen activator, urokinase } \\
\text { receptor (PLAUR), mRNA }\end{array}$ \\
\hline & PTX3 & NM 002852 & $\begin{array}{l}\text { Homo sapiens pentaxin-related gene, rapidly induced } \\
\text { by IL-I beta (PTX3), mRNA }\end{array}$ \\
\hline & $S I 00 A / 2$ & NM $17465 \mid$ & $\begin{array}{l}\text { Bos taurus SI00 calcium binding protein } \mathrm{A} 12 \\
\text { (calgranulin C) (SI00AI2), mRNA }\end{array}$ \\
\hline & SIOOA2 & NM 005978 & $\begin{array}{l}\text { Homo sapiens SI00 calcium binding protein A2 } \\
\text { (SI00A2), mRNA }\end{array}$ \\
\hline & THBSI & NM_174196 & Homo sapiens thrombospondin I (THBSI), mRNA \\
\hline \multicolumn{4}{|c|}{ Cell surface receptors } \\
\hline & CCRI & $\underline{N M \quad 001295}$ & $\begin{array}{l}\text { Homo sapiens chemokine (C-C motif) receptor I } \\
\text { (CCRI), mRNA }\end{array}$ \\
\hline & $C D / 4$ & NM 000591 & Homo sapiens CDI4 antigen (CDI4), mRNA \\
\hline & CD40 & NM 152854 & $\begin{array}{l}\text { Homo sapiens tumor necrosis factor receptor } \\
\text { superfamily, member } 5 \text { (TNFRSF5), transcript }\end{array}$ \\
\hline & CSF3R & NM 172313 & $\begin{array}{l}\text { Homo sapiens colony stimulating factor } 3 \text { receptor } \\
\text { (granulocyte) (CSF3R), transcript variant }\end{array}$ \\
\hline & ILIIRA & NM 147162 & $\begin{array}{l}\text { Homo sapiens interleukin II receptor, alpha } \\
\text { (ILI IRA), transcript variant 2, mRNA }\end{array}$ \\
\hline & SLC2A4 & NM 001042 & $\begin{array}{l}\text { Homo sapiens solute carrier family } 2 \text { (facilitated } \\
\text { glucose transporter), member } 4 \text { (SLC2A4) }\end{array}$ \\
\hline & $T L R 2$ & NM 003264 & Homo sapiens toll-like receptor 2 (TLR2), mRNA \\
\hline & TLR4 & NM 138557 & $\begin{array}{l}\text { Homo sapiens toll-like receptor } 4 \text { (TLR4), transcript } \\
\text { variant } 4 \text {, mRNA }\end{array}$ \\
\hline & TNFRSF9 & NM 001561 & $\begin{array}{l}\text { Homo sapiens tumor necrosis factor receptor } \\
\text { superfamily, member } 9 \text { (TNFRSF9), mRNA }\end{array}$ \\
\hline \multicolumn{4}{|c|}{ Intracellular signaling } \\
\hline & CDKNIA & NM 078467 & $\begin{array}{l}\text { Homo sapiens cyclin-dependent kinase inhibitor IA } \\
\text { (p2I, CipI) (CDKNIA), transcript variant 2, mRNA }\end{array}$ \\
\hline & FGD6 & $\underline{\mathrm{AC} 009159}$ & $\begin{array}{l}\text { Homo sapiens FYVE, RhoGEF and PH domain } \\
\text { containing } 6 \text { (FGD6), mRNA }\end{array}$ \\
\hline & MTMRIO & A 5667991 & $\begin{array}{l}\text { Homo sapiens hypothetical protein FLJ203I3 } \\
\text { (FLJ203।3), mRNA }\end{array}$ \\
\hline
\end{tabular}


Table 3: Significantly up-regulated genes in mammary tissue challenged with S. aureus. (Continued)

\begin{tabular}{|c|c|c|c|}
\hline & HCK & NM 002110 & $\begin{array}{l}\text { Homo sapiens hemopoietic cell kinase (HCK), } \\
\text { mRNA }\end{array}$ \\
\hline & MARCKS & NM 002356 & $\begin{array}{l}\text { Homo sapiens myristoylated alanine-rich protein } \\
\text { kinase } C \text { substrate (MARCKS), mRNA }\end{array}$ \\
\hline & MARCKSLI & NM 023009 & Homo sapiens MARCKS-like protein (MLP), mRNA \\
\hline & ZFYVE9 & NM 007324 & $\begin{array}{l}\text { Homo sapiens MAD, mothers against } \\
\text { decapentaplegic homolog (Drosophila) interacting }\end{array}$ \\
\hline \multicolumn{4}{|l|}{ Apoptosis } \\
\hline & BAT3 & NM 174196 & $\begin{array}{l}\text { Homo sapiens HLA-B associated transcript } 3 \text { (BAT3), } \\
\text { transcript variant 3, mRNA }\end{array}$ \\
\hline & $B C L 2 A I$ & NP 004040 & $\begin{array}{l}\text { Homo sapiens BCL2-related protein AI (BCL2AI), } \\
\text { mRNA }\end{array}$ \\
\hline & BIRC3 & NM 182962 & $\begin{array}{l}\text { Homo sapiens baculoviral IAP repeat-containing } 3 \\
\text { (BIRC3), transcript variant 2, mRNA }\end{array}$ \\
\hline & IER3 & NM 003897 & $\begin{array}{l}\text { Homo sapiens immediate early response } 3 \text { (IER3), } \\
\text { transcript variant short, mRNA }\end{array}$ \\
\hline \multicolumn{4}{|l|}{ Transcription factor or regulator } \\
\hline & ATF3 & NM 001674 & $\begin{array}{l}\text { Homo sapiens activating transcription factor } 3 \\
\text { (ATF3), mRNA }\end{array}$ \\
\hline & BTG2 & NM 006763 & $\begin{array}{l}\text { Homo sapiens BTG family, member } 2 \text { (BTG2), } \\
\text { mRNA }\end{array}$ \\
\hline & $E G R I$ & NM 001964 & $\begin{array}{l}\text { Homo sapiens early growth response I (EGRI), } \\
\text { mRNA }\end{array}$ \\
\hline & FOS & NM 005252 & $\begin{array}{l}\text { Homo sapiens v-fos FBJ murine osteosarcoma viral } \\
\text { oncogene homolog (FOS), mRNA }\end{array}$ \\
\hline & JUNB & NM 002229 & Homo sapiens jun B proto-oncogene (JUNB), mRNA \\
\hline & NFKB2 & NM 002502 & $\begin{array}{l}\text { Homo sapiens nuclear factor of kappa light } \\
\text { polypeptide gene enhancer in B-cells }\end{array}$ \\
\hline & NFKBIA & NM 020529 & $\begin{array}{l}\text { Homo sapiens nuclear factor of kappa light } \\
\text { polypeptide gene enhancer in B-cells inhibitor }\end{array}$ \\
\hline & NR2F6 & AF338825 & $\begin{array}{l}\text { Homo sapiens nuclear receptor subfamily } 2 \text {, group } F \text {, } \\
\text { member } 6 \text { (NR2F6), mRNA }\end{array}$ \\
\hline \multicolumn{4}{|l|}{ Assorted } \\
\hline & ACSL6 & NM 015256 & $\begin{array}{l}\text { Homo sapiens acyl-CoA synthetase long-chain family } \\
\text { member } 6 \text { (ACSL6), mRNA }\end{array}$ \\
\hline & FUT8 & NM 17750I & $\begin{array}{l}\text { Homo sapiens fucosyltransferase } 8 \text { (alpha }(I, 6) \\
\text { fucosyltransferase) (FUT8), transcript }\end{array}$ \\
\hline & HSPAIA & NM 005345 & $\begin{array}{l}\text { Homo sapiens heat shock } 70 \text { kDa protein IA } \\
\text { (HSPAIA), mRNA }\end{array}$ \\
\hline & MGC2I88I & $\underline{X P \quad 219130}$ & $\begin{array}{l}\text { Homo sapiens hypothetical protein LOC286286 } \\
\text { (LOC286286), mRNA }\end{array}$ \\
\hline & NOS $2 A$ & NM 000625 & $\begin{array}{l}\text { Homo sapiens nitric oxide synthase } 2 \mathrm{~A} \text { (inducible, } \\
\text { hepatocytes) (NOS2A), transcript variant }\end{array}$ \\
\hline & SOD2 & $\underline{\mathrm{L} 22092}$ & $\begin{array}{l}\text { Homo sapiens superoxide dismutase } 2 \\
\text { mitochondrial (SOD2), mRNA }\end{array}$ \\
\hline & TIMPI & NM 003254 & $\begin{array}{l}\text { Homo sapiens tissue inhibitor of metalloproteinase I } \\
\text { (erythroid potentiating activity, collagenase) }\end{array}$ \\
\hline & TUBAI & NM 006000 & $\begin{array}{l}\text { Homo sapiens tubulin, alpha I (testis specific) } \\
\text { (TUBAI), mRNA }\end{array}$ \\
\hline & WARS & NM_174218 & $\begin{array}{l}\text { Homo sapiens tryptophanyl-tRNA synthetase } \\
\text { (WARS), mRNA }\end{array}$ \\
\hline
\end{tabular}

bits, which were used to test whether S100A12 and PTX3 were present in milk samples from infected cows.

\section{Identification of SIOOAI 2 and PTX3 in milk from cows with intramammary $S$. aureus infection}

Figure 6 shows immunoblots of milk whey taken from control udder quarters or udder quarters infected with $S$. aureus at doses of $1 \times 10^{5}$ and $1 \times 10^{6}$ bacteria for $16 \mathrm{~h}$. The antibodies used were immunoaffinity-purified antibodies raised to purified rS100A12 or rPTX3. In each case there was little or no detectable immunoreactivity in the milk whey samples from the uninfected controls or samples from udder quarters taken prior to the experimental infections. S100A12 and PTX3 immunoreactive bands were 
Table 4: Significantly down-regulated genes in mammary tissue challenged with S. aureus.

\begin{tabular}{|c|c|c|c|}
\hline Function & Gene symbol & Genbank accession & Genbank description \\
\hline \multicolumn{4}{|c|}{$\begin{array}{l}\text { Chemokine, cytokine and } \\
\text { intercellular signalling }\end{array}$} \\
\hline & ILIA & $\underline{M 37210}$ & Bovine interleukin I-alpha (IL-I-alpha) mRNA, complete cds. \\
\hline & NGFB & NM 002506 & $\begin{array}{l}\text { Homo sapiens nerve growth factor, beta polypeptide (NGFB), } \\
\text { mRNA }\end{array}$ \\
\hline & ILI3 & AF072807 & Bos taurus interleukin-13 precursor (IL-I3) mRNA, partial cds \\
\hline & RETN & NM 183362 & Bos taurus resistin (RETN), mRNA \\
\hline & SFRPI & NM 003012 & $\begin{array}{l}\text { Homo sapiens secreted frizzled-related protein I (SFRPI), } \\
\text { mRNA }\end{array}$ \\
\hline & SPPI & AF492837 & $\begin{array}{l}\text { Homo sapiens secreted phosphoprotein I (osteopontin, bone } \\
\text { sialoprotein I, early T-lymphocyte activation I) (SPPI), mRNA }\end{array}$ \\
\hline \multicolumn{4}{|c|}{$\begin{array}{c}\text { Cytoskeleton and extracellular } \\
\text { matrix }\end{array}$} \\
\hline & $C D 24$ & NM 013230 & $\begin{array}{l}\text { Homo sapiens CD24 antigen (small cell lung carcinoma cluster } \\
4 \text { antigen) (CD24), }\end{array}$ \\
\hline & EPB4ILI & NM 174528 & $\begin{array}{l}\text { Homo sapiens erythrocyte membrane protein band } 4.1 \text {-like I } \\
\text { (EPB4ILI), transcript }\end{array}$ \\
\hline & FLNA & NM 001456 & $\begin{array}{l}\text { Homo sapiens filamin A, alpha (actin binding protein 280) } \\
\text { (FLNA), mRNA }\end{array}$ \\
\hline & ITGA3 & NM 002204 & $\begin{array}{l}\text { Homo sapiens integrin, alpha } 3 \text { (antigen CD49C, alpha } 3 \\
\text { subunit of VLA-3 receptor }\end{array}$ \\
\hline & ITGB4 & NM 000213 & $\begin{array}{l}\text { Homo sapiens v-kit Hardy-Zuckerman } 4 \text { feline sarcoma viral } \\
\text { oncogene homolog }\end{array}$ \\
\hline & KRT5 & $\underline{\mathrm{BC} 006780}$ & $\begin{array}{l}\text { Homo sapiens keratin } 5 \text { (epidermolysis bullosa simplex, } \\
\text { Dowling-Meara/Kobner/Weber }\end{array}$ \\
\hline & PFN2 & NM 053024 & Homo sapiens profilin 2 (PFN2), transcript variant I, mRNA \\
\hline & VCAMI & NM 174484 & $\begin{array}{l}\text { Homo sapiens vascular cell adhesion molecule I (VCAMI), } \\
\text { transcript variant } 2, \text { mRNA }\end{array}$ \\
\hline & $V C L$ & NM 014000 & $\begin{array}{l}\text { Homo sapiens vinculin (VCL), transcript variant meta-VCL, } \\
\text { mRNA }\end{array}$ \\
\hline & VIM & NM 003380 & Homo sapiens vimentin (VIM), mRNA \\
\hline \multicolumn{4}{|c|}{ Cell surface receptors } \\
\hline & CX3CRI & NM 001337 & $\begin{array}{l}\text { Homo sapiens chemokine (C-X3-C motif) receptor I } \\
(\text { CX3CRI), mRNA }\end{array}$ \\
\hline & ERBB4 & NM 005235 & $\begin{array}{l}\text { Homo sapiens v-erb-a erythroblastic leukemia viral oncogene } \\
\text { homolog } 4 \text { (avian) }\end{array}$ \\
\hline & FGFRI & NM 023106 & $\begin{array}{l}\text { Homo sapiens fibroblast growth factor receptor I (fms-related } \\
\text { tyrosine kinase 2) }\end{array}$ \\
\hline & KIT & NM 000222 & $\begin{array}{l}\text { Homo sapiens v-kit Hardy-Zuckerman } 4 \text { feline sarcoma viral } \\
\text { oncogene homolog (KIT) }\end{array}$ \\
\hline & MET & $\underline{\mathrm{V} 00654}$ & $\begin{array}{l}\text { Homo sapiens met proto-oncogene (hepatocyte growth factor } \\
\text { receptor) (MET), mRNA }\end{array}$ \\
\hline & PDGFRA & NM 006206 & $\begin{array}{l}\text { Homo sapiens platelet-derived growth factor receptor, alpha } \\
\text { polypeptide (PDGFRA) }\end{array}$ \\
\hline & TGFBR3 & NM 003243 & $\begin{array}{l}\text { Homo sapiens transforming growth factor, beta receptor III } \\
\text { (betaglycan, } 300 \mathrm{kDa} \text { ) }\end{array}$ \\
\hline \multicolumn{4}{|c|}{ Intracellular signaling } \\
\hline & $P P$ & M95283 & Homo sapiens pyrophosphatase (inorganic) (PP), mRNA \\
\hline & PPMIJ & NM 005167 & $\begin{array}{l}\text { Homo sapiens protein phosphatase IJ (PP2C domain } \\
\text { containing) (PPMIJ), mRNA }\end{array}$ \\
\hline & PRKCA & NM 174435 & Homo sapiens protein kinase $\mathrm{C}$, alpha (PRKCA), mRNA \\
\hline & RHOB & NM 004040 & $\begin{array}{l}\text { Homo sapiens ras homolog gene family, member B (RHOB), } \\
\text { mRNA }\end{array}$ \\
\hline \multicolumn{4}{|l|}{ Apoptosis } \\
\hline & CIDEA & NM 001279 & $\begin{array}{l}\text { Homo sapiens cell death-inducing DFFA-like effector a } \\
\text { (CIDEA), transcript variant }\end{array}$ \\
\hline & CLU & NM 173902 & Bos taurus clusterin (CLU), mRNA. \\
\hline & EPHAI & NM 005232 & Homo sapiens EphAI (EPHAI), mRNA \\
\hline
\end{tabular}


Table 4: Significantly down-regulated genes in mammary tissue challenged with S. aureus. (Continued)

\begin{tabular}{|c|c|c|c|}
\hline & EPHA7 & NM 004440 & Homo sapiens EphA7 (EPHA7), mRNA \\
\hline \multicolumn{4}{|l|}{ Transcription factor or regulator } \\
\hline & DDX5 & NM 004396 & $\begin{array}{l}\text { Homo sapiens DEAD (Asp-Glu-Ala-Asp) box polypeptide } 5 \\
\text { (DDX5), mRNA }\end{array}$ \\
\hline & NFATC4 & NM 004554 & $\begin{array}{l}\text { Homo sapiens nuclear factor of activated T-cells, cytoplasmic, } \\
\text { calcineurin-dependent }\end{array}$ \\
\hline & TEBP & NM 006601 & $\begin{array}{l}\text { Homo sapiens inactive progesterone receptor, } 23 \text { kD (TEBP), } \\
\text { mRNA }\end{array}$ \\
\hline \multicolumn{4}{|l|}{ Assorted } \\
\hline & CAMP & NM 174825 & $\begin{array}{l}\text { Homo sapiens cathelicidin antimicrobial peptide (CAMP), } \\
\text { mRNA }\end{array}$ \\
\hline & CSNISI & NM 181029 & Homo sapiens casein alpha sI (CSNISI), mRNA \\
\hline & FLJ20920 & NM 025149 & $\begin{array}{l}\text { Homo sapiens hypothetical protein FLJ20920 (FLJ20920), } \\
\text { mRNA }\end{array}$ \\
\hline & GATM & NM 001482 & $\begin{array}{l}\text { Homo sapiens glycine amidinotransferase (L-arginine:glycine } \\
\text { amidinotransferase }\end{array}$ \\
\hline & GPX4 & NM 002085 & $\begin{array}{l}\text { Homo sapiens glutathione peroxidase } 4 \text { (phospholipid } \\
\text { hydroperoxidase) (GPX4) }\end{array}$ \\
\hline & LOC529035 & AFI09167 & $\begin{array}{l}\text { Bos taurus immunoglobulin IgA heavy chain constant region } \\
\text { gene, partial cds }\end{array}$ \\
\hline & I8S rRNA & AYI50548 & Cervus nippon $18 \mathrm{~S}$ ribosomal RNA gene, partial sequence \\
\hline & SNX19 & $\underline{\mathrm{ACI} 50499}$ & $\begin{array}{l}\text { Homo sapiens similar to Sorting nexin } 19 \text { (LOC399979), } \\
\text { mRNA }\end{array}$ \\
\hline
\end{tabular}

identified in all samples obtained from the infected quarters of the three tested cows. For cow 1419, three S100A12 immunoreactive bands were detected corresponding to monomer $(\mathrm{Mr} \sim 11 \mathrm{kDa})$, dimer $(\mathrm{Mr} \sim 22 \mathrm{kDa})$ and trimer ( $\mathrm{Mr} \sim 33 \mathrm{kDa}$ ), despite the sample being reduced (Fig. 6(a)). The predicted size of bovine S100A12 is $10.7 \mathrm{kDa}$. The dimeric form was predominant. Human S100A12 exists as a highly stable dimer [42]. Similar results were also obtained for milk samples from cows 1490 and 1592. For PTX3, the predominant immunoreactive band was the dimeric form of PTX3 ( $\mathrm{Mr} \sim 90 \mathrm{kDa}$ ), again despite the sample being run under reducing conditions. Monomeric PTX3 ( $\mathrm{Mr} \sim 45 \mathrm{kDa}$ ) was also discernable (Fig. 6(b)). The predicted Mw of the mature PTX3 protein is $40.2 \mathrm{kDa}$. The bovine PTX3 predicted amino acid sequence contains one potential N-linked glycosylation site $\left(\mathrm{Asn}_{221}\right)$ and indeed this type of glycosylation is present on the PTX3 protein derived from other species [43]. Close examination of the dimeric immunoreactive band reveals micro-heterogeneity that could reflect differential glycosylation or the formation of mixed intramolecular disulphide bonds. The latter could result from re-oxidation of cysteine residues during the electrophoretic separation process. For cow 1419 the immunoreactive bands were more intense at the bacterial dose of $1 \times 10^{6}$ compared to $1 \times 10^{5}$. This result was consistent with the corresponding transcriptional changes (Fig. 1(c)) and measurements of the quantities of this protein in milk whey samples using an antigen capture ELISA (see below). The absence of S100A12 and PTX3 immunoreactivities in milk from both the control udder quarter and the pre-infection samples from cow 1419 indicates that the low level $S$. aureus infection detected in one (unused) udder quarter of this cow $24 \mathrm{~h}$ prior to the commencement of the experimental infection had not influenced the remaining quarters. Further, these data indicate that the experimental infection in one quarter did not influence the adjacent control udder quarter under these conditions.

Quantification of SI OOAI 2 and PTX3 proteins in milk from cows subjected to intramammary infection with $S$. aureus Antigen specific enzyme-linked immunosorbent assays (ELISAs) were developed to measure the quantities of S100A12 and PTX3 in milk samples taken from udder quarters after $S$. aureus intramammary challenges of the three cows (Fig. 7). Significantly increased S100A12 protein expression $(\mathrm{P}<0.01)$ was detected in the milk whey from the infected udders in all three cows relative to their respective intramammary control quarters (at $16 \mathrm{~h}$ postinfection). There was a low level of S100A12 expression in milk samples from the control non-infected udders. Moreover, there was a relatively small but significantly ( $\mathrm{P}$ $<0.01$ ) higher level of S100A12 in milk from the control udder quarters $16 \mathrm{~h}$ post-infection compared with the corresponding pre-infection samples. Thus, using this antigen capture ELISA there was evidence for a small intermammary quarter effect on S100A12 levels in milk.

The responses to infection in the different cows were varied. Cow 1419 had a concentration of $420 \mathrm{ng} / \mathrm{ml}$ of S100A12 in milk from the control udder at $16 \mathrm{~h}$ postinfection while the S100A12 levels in the udders that had been challenged with $1 \times 10^{5}$ and $1 \times 10^{6}$ bacteria were almost five times greater $(1920 \mathrm{ng} / \mathrm{ml}$ in the milk from both udder quarters) $(\mathrm{P}<0.01)$. Cow 1490 had lower levels of S100A12 in the control udder $(90 \mathrm{ng} / \mathrm{ml})$ and the 


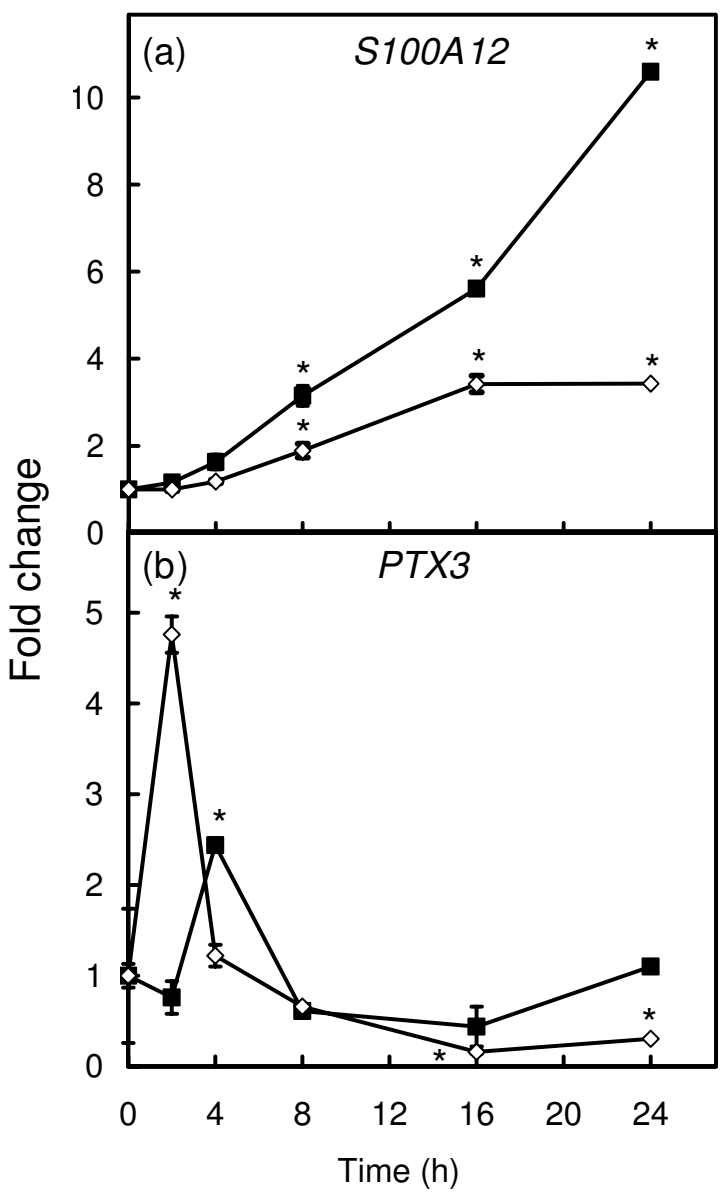

Figure 4

Time-courses of SIOOAI 2 and PTX3 expression in bMEC stimulated with LPS and LTA. bMEC were stimulated with either $50 \mu \mathrm{g} / \mathrm{ml}$ LPS ( $\square$ ) or $20 \mu \mathrm{g} / \mathrm{ml} \mathrm{LTA} \mathrm{()} \mathrm{and}$ the expression levels of SIOOAI 2 (a) and PTX3 (b) were monitored using qRT-PCR over a $24 \mathrm{~h}$ period. Data are expressed as mean fold change $(n=3)$ compared to expression in unstimulated cells. Significance was determined by ANOVA compared to unstimulated bMEC. P $<0.01\left(^{*}\right)$ was considered significant.

levels of S100A12 increased in a dose-dependent manner $(\mathrm{P}<0.01)$. The S100A12 protein expression was relatively high in milk from udder quarters infected with bacterial doses of $1 \times 10^{5}$ and $1 \times 10^{6}$ in cow $1592(918 \mathrm{ng} / \mathrm{ml}$ and $1000 \mathrm{ng} / \mathrm{ml}$, respectively) $(\mathrm{P}<0.01)$ while the quantities of S100A12 detected in milk from the udder quarter challenged with the lowest dose of $1 \times 10^{4}$ bacteria (140 ng/ $\mathrm{ml}$ ) was not significantly different from the control udder $(150 \mathrm{ng} / \mathrm{ml})$.
Increased concentrations of PTX 3 were detected in milk whey from the infected udders in all three cows compared to their intramammary quarters (Fig. 7(b)). PTX3 could not be detected in milk from the pre-infection udders or the post-infection control udders. Cow 1419 showed the highest levels of PTX3 in milk from the udder quarters that had been challenged with $1 \times 10^{5}$ and $1 \times 10^{6}$ bacteria $(4.6 \mu \mathrm{g} / \mathrm{ml}$ and $14.2 \mu \mathrm{g} / \mathrm{ml}$, respectively). Cow $1490 \mathrm{had}$ less marked, but still significantly $(\mathrm{P}<0.01)$ increased levels of PTX3 in response to the bacterial dose of $1 \times 10^{5}$ (i.e. $3 \mu \mathrm{g} / \mathrm{ml}$ ). The quantities of PTX3 detected in milk from the udder quarters of cow 1592 challenged with the two higher bacterial doses, $1 \times 10^{5}$ and $1 \times 10^{6}$ of $S$. aureus, were significantly $(\mathrm{P}<0.01)$ increased (i.e. $2.7 \mu \mathrm{g} / \mathrm{ml}$ and $1.6 \mu \mathrm{g} / \mathrm{ml}$ respectively).

\section{Correlation between the Somatic Cell Count (SCC) and SIOOAI 2 protein expression in milk from dairy cows}

The S100A12 protein levels in milk were measured using the S100A12-specific antigen capture ELISA and correlated with the milk somatic cell count (SCC) from a selection of 38 dairy cows with SCC ranging from $1 \times 10^{4}-3 \times$ $10^{6}$ cells $/ \mathrm{ml}$ (Fig. 8). There was a linear correlation between S100A12 quantity in milk and milk SCC $\left(\mathrm{R}^{2}=\right.$ 0.92). The PTX3-specific antigen capture ELISA was not used to examine the correlation between PTX3 quantity in milk and SCC due to the relatively low levels of PTX3 present in all milk samples.

\section{Recombinant SIOOAI2 has anti-microbial activity against E. coli}

A previous publication suggested that human S100A12 may have anti-microbial activity [44]. The capacity of recombinant bovine S100A12 (rS100A12) to inhibit $E$. coli growth was examined using a microtiter dilution antimicrobial susceptibility testing assay [45]. Inhibition of growth of E. coli (strain LE392) was observed in the rS100A12 concentration range of $12.5-50 \mu \mathrm{g} / \mathrm{ml}(\mathrm{P}<$ 0.05) (Fig. 9(a)). The greatest inhibitory activity was observed using $25 \mu \mathrm{g} / \mathrm{ml}$ of $\mathrm{rS} 100 \mathrm{~A} 12$, which resulted in a 2.3 fold reduction in optical density of the $E$. coli culture. Under the same conditions rS100A12 did not significantly $(\mathrm{P}>0.05)$ affect the growth of S. aureus (ATCC 25923) at any concentration (Fig. 9(b)).

\section{Expression of recombinant bovine PTX3 in Trichoplusia ni insect cells}

Recombinant bovine PTX3 (rtnPTX3) was also produced in insect cells to obtain a correctly folded and biologically active protein. The culture supernatant from the Trichoplusia ni (High Five ${ }^{\mathrm{TM}}$ ) insect cells transfected with the pIEX5PTX3 construct was analysed by SDS-PAGE and immunobloting under reducing conditions. Immunoreactive pro- 
(a)

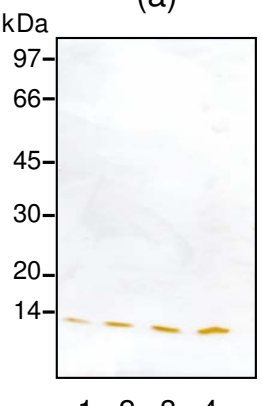

$\begin{array}{llll}1 & 2 & 3 & 4\end{array}$ (b)

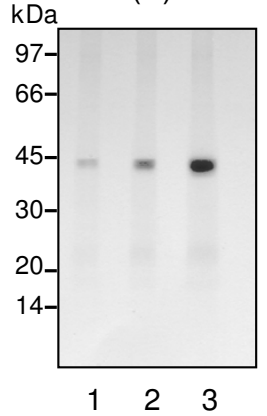

(c)

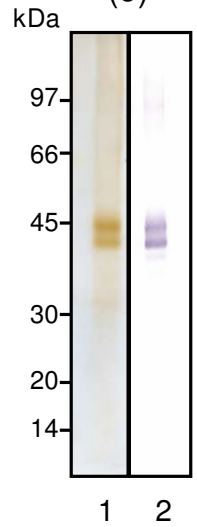

\section{Figure 5}

Purified SIOOAI 2 and PTX3 recombinant proteins. (a) SDS-PAGE analysis of rSI00A I 2 purified using Ni-NTA affinity chromatography. All samples were run under reduc-

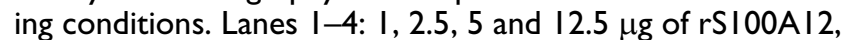
respectively. (b) SDS-PAGE analysis of rPTX3 purified using Ni-NTA affinity chromatography. The samples were reduced and alkylated, and run under reducing conditions. Lanes I-3: I, 2 and $4 \mu \mathrm{g}$ of rPTX3, respectively. (c) SDS-PAGE (lane I) and immunoblot (lane 2) analyses of purified rtnPTX3 secreted by Trichoplusia ni cells. The samples were reduced and alkylated and run under reducing conditions. $10 \mu \mathrm{g}$ of rtnPTX 3 was used for the SDS-PAGE analysis and $5 \mu \mathrm{g}$ for the immunoblot.

teins with an apparent molecular size of $45 \mathrm{kDa}$ (monomer) and $90 \mathrm{kDa}$ (dimer) were present but not observed in the culture supernatant from the plasmidonly control (results not shown). rtnPTX3 produced by these cells was purified from the culture supernatant using anion exchange chromatography. Figure 5(c) shows silver-stained SDS-PAGE and immunoblot analyses of purified rtnPTX3 after reduction and alkylation. The purified protein was represented by two equal staining bands of Mr $43 \mathrm{kDa}$ and $45 \mathrm{kDa}$ compared with a predicted size for the mature protein of $40.2 \mathrm{kDa}$. The PTX3 sequence has a potential $N$-linked glycosylation site at amino acid position $221\left(\mathrm{~N}_{221}\right)$ and hence the larger band may reflect a more glycosylated form of the protein. N-terminal sequencing of rtnPTX3, from both bands, showed identity with the predicted amino acid sequence of the mature bovine PTX3 polypeptide (GenPept accession AAI20176). The mature PTX3 protein sequence contains nine cysteine residues, which may mediate formation of multimers [43]. Indeed, rtnPTX3 was present in solution as a large oligomer (decamer) as defined by gel permeation chromatography (result not shown).

\section{Purified rtnPTX3 binds the CIq component of the human complement system}

The binding of human PTX3 expressed in Chinese Hamster Ovary ( $\mathrm{CHO}$ ) cells to human $\mathrm{C1q}$ has been previously demonstrated $[43,46]$. To characterise the binding of rtnPTX3 to C1q, dilutions of two different preparations of purified rtnPTX3 were added to $500 \mathrm{ng}$ of immobilised human C1q and after washing bound rtnPTX3 was measured. Figure 10 demonstrates that rtnPTX3 bound to human $\mathrm{C} 1 \mathrm{q}$ compared to either the BSA or PBS control (Fig. 10).

\section{rtnPTX3 binds E. coli}

rtnPTX3 was tested for ability to inhibit the growth of $E$. coli (strain LE392) or S. aureus (ATCC 25923) using the assay described for rS100A12. No direct activity could be demonstrated. However, it has been reported that human PTX3 binds selected pathogens including Pseudomonas aeruginosa, Salmonella typhimurium and Aspergillus fumigatus [47]. To investigate the possibility that bovine rtnPTX3 binds $E$. coli, the protein was bound to nitrocellulose in a slot blot and then probed with biotinylated E. coli. The slot blot showed that biotinylated E. coli in PBS bound to rtnPTX3 but not the same quantity of BSA (Fig. 11). Biotinylated $S$. aureus $\left(1 \times 10^{9}\right.$ bacteria $)$ in PBS did not bind to the immobilised rtnPTX3 (result not shown).

\section{Discussion}

The objective of this study was to characterise the host transcriptional response to intra-mammary infection with S. aureus, a Gram-positive bacterial pathogen. We initially investigated the mRNA expression levels of two major milk protein genes (CSN1S1 and CSN2) in the udder tissue to confirm that transcripts encoding proteins involved in the major physiological function of the udder, milk protein production, were not affected by the experimental infection. These qRT-PCR measurements demonstrated that the limited experimental infection, in terms of infection time and dose, had not caused significant loss of function in the mammary tissue. Thus, the experimental model measured changes in immune gene responses that are likely to be appropriate for the initial stages of infection.

Transcript profiling was employed to analyse gene expression in mammary tissue challenged by $S$. aureus infection. Initially, mRNA levels of a number of genes (CD14, IL-1 $\beta$, $I L-6, I L-8$ and TNF $\alpha$ ), principally encoding proinflammatory cytokines, were measured. These genes showed significant dose-dependent up-regulation in all three cows subjected to intramammary infusion with $S$. aureus for a $16 \mathrm{~h}$ period. The dose dependent transcriptional responses probably directly reflect the dose of bacteria in the tissue and also, due to the lag phase in bacterial growth, different durations of inflammation in the tissue. 
This experiment also demonstrated that $S$. aureus intramammary infusion had generated an immune response that was self-contained within each udder quarter i.e. the experimental infection in one udder quarter did not affect gene expression in the adjacent control udder quarter. Although TNF $\alpha$ mRNA, measured by qRT-PCR, was up-regulated by the intramammary infusion of $S$. aureus, it has been reported that the protein was not detectable in milk from udders infected with $S$. aureus $[48,49]$. One possible explanation is that this apparent disparity reflects the differing sensitivities and dynamic ranges of the measurement technologies. Another possibility is that the observed changes in mRNA expression for TNF $\alpha$ do not accurately translate into corresponding secreted protein changes. This could occur when mRNA translation or protein secretion were rate limiting in defining the quantity of TNF $\alpha$ in milk.
The reasons for the more accentuated responses in cow 1419 are not clear but may reflect differing genetics underlying individual immune responsiveness or a different history of disease exposure. It is also possible that cow 1419 had been primed for a stronger innate immune response as a result of a low level of asymptomatic preexisting infection in one quarter prior to the experimental challenge, despite this quarter not being used in the experiment. However, the control quarter from this cow did not display increased expression of TNF $\alpha$ or $I L-8$ relative to the controls from the other two cows, indicating that expression of genes in the control quarter from cow 1419 was not systemically affected by a pre-existing mild infection in the unused adjacent quarter. Another possibility is that the infection was not uniform in the udder quarter and sampling had occurred in regions from this animal that had a greater extent of infection.
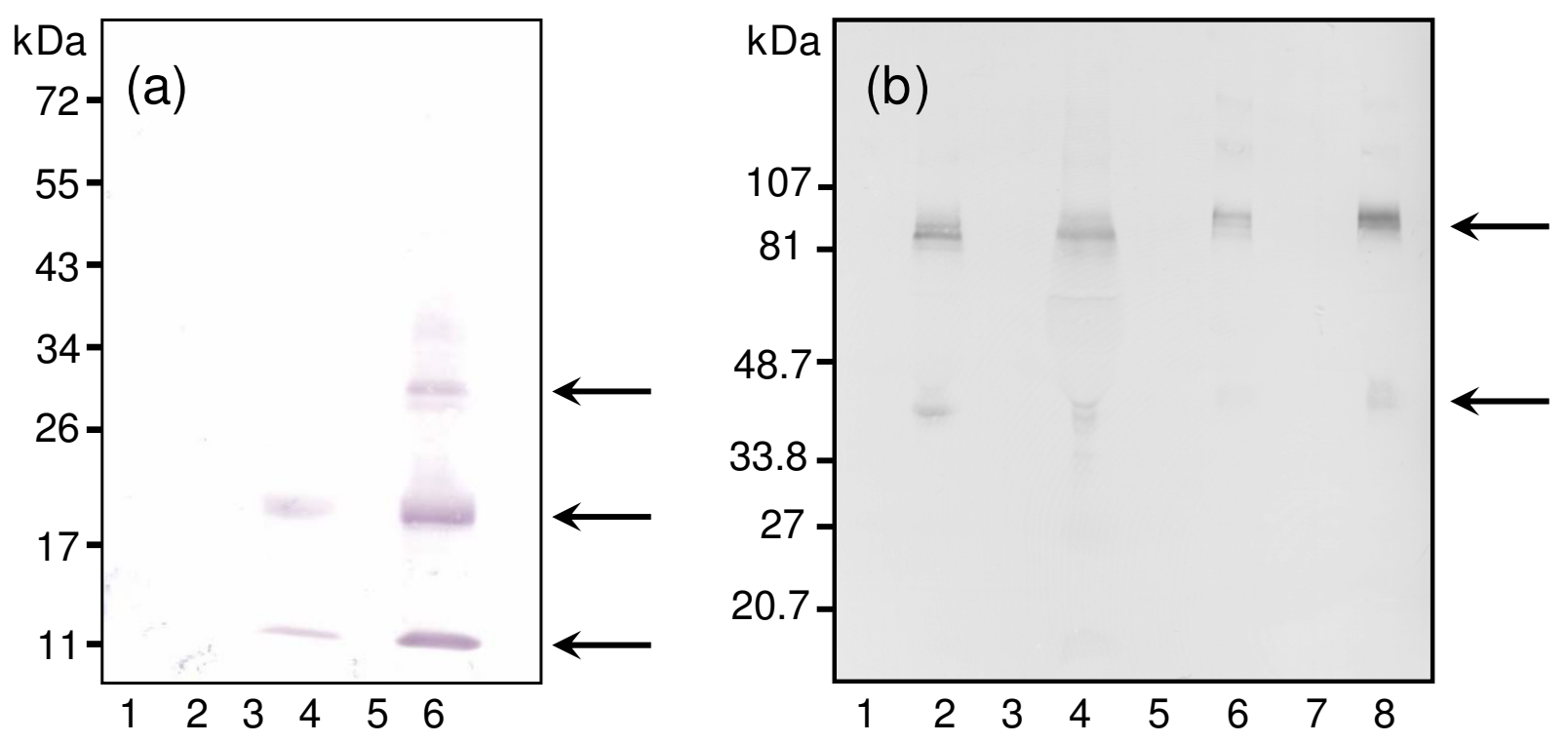

\section{Figure 6}

Immunoblot analyses of SIO0AI 2 and PTX3 expression in milk whey from S. aureus infected cattle. Representative immunoblot analyses of milk whey proteins before and after infection of mammary tissue with $S$. aureus. Each sample comprised $25 \mu \mathrm{l}$ of milk whey and was run under reducing conditions. (a) Representative analysis of SI00AI 2 expression in milk whey from cow 1419. Lane I, control quarter pre-infection; lane 2, control quarter post-infection; lane 3, pre-infection control from the quarter receiving $I \times 10^{5} \mathrm{~S}$. aureus; lane 4, post-infection sample $\left(1 \times 10^{5}\right.$ bacteria); lane 5 , pre-infection control from the quarter receiving I $\times 10^{6} \mathrm{~S}$. aureus; lane 6, post-infection sample $\left(\mathrm{I} \times 10^{6}\right.$ bacteria $)$. Arrows denote the positions of SIOOAI2 immunoreactive oligomers (monomer, dimer, trimer) detected using the immunoaffinity purified antibodies raised to rSI00A 12. (b) Analysis of PTX3 expression in milk whey. Lane I, cow I4I9 pre-infection sample from the quarter receiving I $\times 10^{5} \mathrm{~S}$. aureus; lane 2, post-infection sample ( $\times 10^{5}$ bacteria); lane 3, cow 1419 pre-infection sample from the quarter receiving I × $10^{6} \mathrm{~S}$. aureus; lane 4, cow 1419 post-infection sample $\left(I \times 10^{6}\right.$ bacteria); lane 5, cow I490 pre-infection sample from the quarter receiving I × $10^{5} \mathrm{~S}$. aureus; lane 6 , cow 1490 post-infection sample $\left(I \times 10^{5}\right.$ bacteria); lane 7 , cow I592 pre-infection control from the quarter receiving $\mathrm{I} \times 10^{5} \mathrm{~S}$. aureus; lane 8, cow 1592 post-infection sample $\left(\mathrm{I} \times 10^{5}\right.$ bacteria). Arrows denote the positions of PTX3 immunoreactive bands (monomer and dimer) detected using immunoaffinity purified antibodies raised to rPTX3. 
Previous studies have clearly demonstrated that mammary epithelial cells have a robust innate immune capability and thus the observed responses in infected mammary tissue probably reflect transcriptional changes in these cells as well as cellularity changes caused by infiltrating immune cells [12]. It might be expected that the predominant responses would be from the mammary epithelial cells at low infection rates and infiltrating immune cells at the higher doses as they respond to proinflammatory signals generated by the former cells. The relative dissection of these contributions awaits further investigation possibly involving immunolocalizations or in situ mRNA localizations.

Microarray transcript profiling identified two major clusters of differentially expressed genes: genes that were upregulated and down-regulated after infusion of $S$. aureus into the mammary gland. The majority of the up-regulated genes encoded proteins involved in intercellular signalling and a large number of them were cytokines and chemokines (e.g. CXCL1, CXCL2, CXCL10, IL-1 $\beta$, IL-6 and IL-8). These proteins are intimately associated with inflammatory processes and are probably essential for the recruitment and activation of neutrophils into the infected mammary tissue $[12,27,50]$. The overflow of these cells into milk is a widely used marker of mastitis in dairy cows. The down-regulated genes encoded components of the cytoskeleton or extracellular matrix, mediators of apoptosis, cell surface receptors and intercellular signalling proteins. The former group suggests that tissue remodelling of the mammary tissue in response to infection was beginning to occur despite the maintenance of normal milk protein gene expression.

The up-regulated cluster also contained genes encoding proteins with less defined functions. Two such genes, S100A12 and PTX3, were investigated in greater detail as they have been previously implicated in inflammatory responses $[51,52]$ although their specific roles particularly in relation to bovine mammary tissue have not been defined. S100A12 and PTX3 mRNAs were markedly upregulated in bMEC stimulated with LPS and LTA indicating that they may be involved in the initial response of mammary tissue to bacterial infection. However, the time courses of their responses were very different with PTX3 showing earlier up-regulation but unlike S100A12 it did not show a sustained response. Thus, the time course responses of these two genes to the infection were dissimilar.

The S100A12 protein (also known as calgranulin C) triggers a signal transduction cascade that results in activation of the transcriptional co-regulator NF- $\kappa \mathrm{B}$ and consequent expression of pro-inflammatory cytokines [32,53]. Increased expression of S100A12 in bMEC could amplify the pro-inflammatory response in infected mammary tissue and thereby promote the infiltration of neutrophils into the tissue. S100A12 is a small (92 amino acids) calcium-binding protein. Interestingly, its mRNA sequence does not encode a signal sequence even though the protein is present externally to stimulated cells and there is a cell surface receptor, Receptor for Advanced Glycation End products (RAGE), for S100A12 on the surface of many cells [32]. One possibility is that S100A12 is released from cells by an undefined secretory mechanism. Another possibility is that it is released from cells undergoing inflammation-induced cell death. The interaction between S100A12 and RAGE is thought to amplify and propagate the inflammatory response in endothelial cells through increased NF- $\mathrm{B}$ activation and expression of pro-inflammatory cytokines. Blockage of this interaction dampens the response by inhibiting the nuclear translocation of NF- $\kappa \mathrm{B}$ [42]. RAGE is a multi-ligand member of the immunoglobulin superfamily of cell surface molecules that binds to Advanced Glycation End products (AGEs), proinflammatory cytokine-like mediators of the S100/calgranulin family, as well as amphoterin and amyloid- $\beta$ protein [54]. The presence and distribution of RAGE in mammary tissue is unknown.

S100A12 was present in milk samples from S. aureusinfected udder quarters and the level of the protein was dependent on the severity of infection. Relatively low quantities of S100A12 were also found in the milk samples taken prior to the $S$. aureus challenge. Interestingly, using an antigen capture ELISA it was demonstrated that S100A12 levels in milk samples from the control udder quarters at $16 \mathrm{~h}$ post-infection showed a small but significant increase compared to the pre-infection control samples. Thus, there was a small intermammary quarter effect of the infection but this was minor compared to the responses in the infected quarters. In a dairy herd there was significant correlation between the level of milk S100A12 and SCC, a widely accepted indicator of mastitis. Thus, S100A12 protein levels in milk could be used as an indicator of mastitis in dairy cattle.

The current study has also demonstrated that rS100A12 inhibited the growth of $E$. coli but not $S$. aureus in a dosedependent manner (Fig. 9). This novel finding suggests that S100A12 may have a direct role in protecting mammary tissue from infection by coliform bacteria and may play a role in protecting newborn suckling calves from bacterial infections. The detailed nature of this inhibitory activity is yet to be defined. The result is somewhat paradoxical in view of the up-regulation of the expression of this gene in bMEC stimulated with LTA, a Gram positive bacterial cell wall component as well as LPS, a Gram negative bacterial cell wall component. 

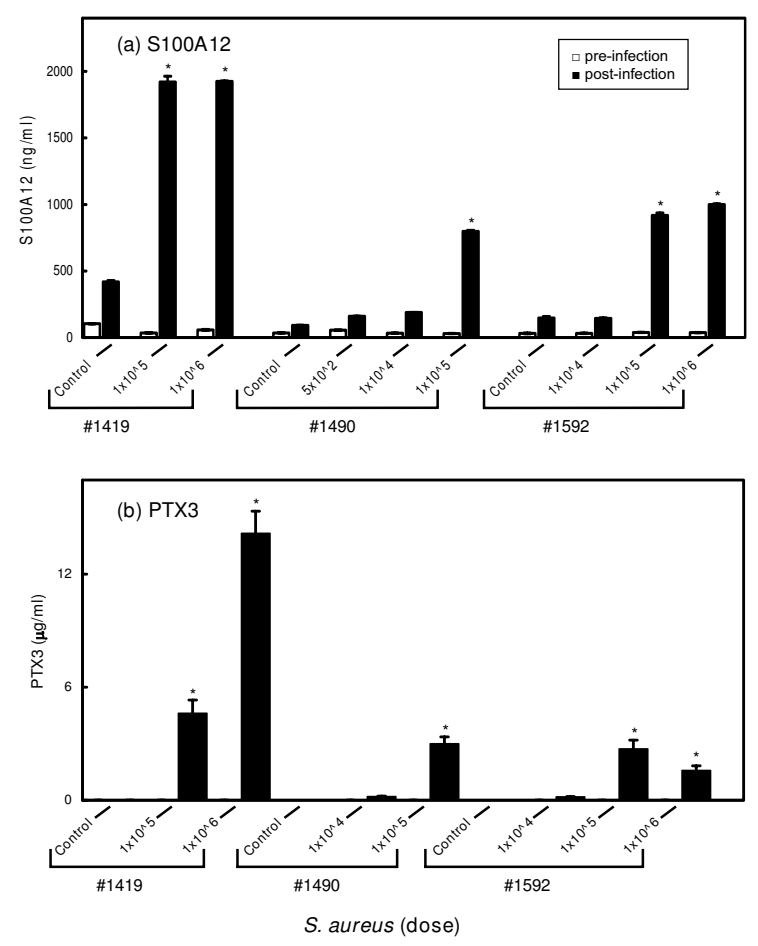

Figure 7

S I O0A 12 and PTX3 expression in milk from S. aureus infected cattle. Antigen capture ELISAs were used to measure the concentrations of SI00AI2 (a) and PTX3 (b) in milk samples taken before and $16 \mathrm{~h}$ after the $S$. aureus intramammary challenge. Data from cows 1419, 1490 and 1592 were used in the analyses. Bars represent the means \pm SEM for two independent samples. The asterisk denotes significant expression difference (I way ANOVA, $P<0.0$ I) compared with the corresponding post-infection control sample for each cow. No PTX3 expression could be detected in milk from the intra-animal control udders or in the pre-infection samples.

The long pentraxin, PTX3, is a secreted multimeric glycoprotein that is thought to activate the immune system by directly binding selected micro-organisms and $\mathrm{C1q}$, the first component of the classical pathway of complement activation $[43,47]$. Indeed, PTX3 is a secreted pattern recognition receptor. The expression of bovine PTX3 mRNA was strongly and rapidly up-regulated in bMEC challenged with LPS and LTA and increased in mammary tissue from udders infected with $S$. aureus. Thus, PTX3 has the characteristics of an innate immune protein. Although no direct anti-bacterial activity could be demonstrated, rtnPTX3 protein was able to directly bind E. coli. This result is consistent with a pattern recognition function of PTX3 that facilitates the immobilisation and display of micro-organisms. The decameric structure of PTX3, partic- ularly its disulphide bonded structure, is thought to underpin this activity $[31,43]$. The bovine recombinant protein also underwent oligomerisation (results not shown). In addition, the current study demonstrated that recombinant bovine PTX3 bound human C1q, thereby physically linking the complement system with PTX3bound bacteria, presumably promoting opsomization of the bacteria. At peak lactation only the alternative complement pathway is active in milk due the absence of C1q. Therefore the actions of PTX3 probably operate only after inflammatory exudation of plasma components into milk [55]. The relatively rapid transcriptional response of bMEC to LTA is consistent with the view that PTX3 is a component of the immediate early response, where it acts to initially bind and coat bacteria, and subsequently activates the classical pathway of the complement system.

\section{Conclusion}

Bovine S100A12 probably amplifies the inflammatory response via recruitment of neutrophils while bovine PTX3 activates the immune system by binding to $\mathrm{C} 1 \mathrm{q}$ and selected pathogens. Acting in concert, these proteins are likely to be important components of a multi-faceted response of mammary tissue to infection. These proteins may lead to novel therapeutic strategies for the treatment and prevention of mastitis. Since S100A12 and PTX3 display microbial growth inhibition and binding properties, respectively, they could provide a new class of natural anti-microbial agents that could assist defense of the mammary gland against chronic and subclinical infections. The presence of these innate immune signalling proteins, amongst other cytokines, in milk may also be instructive for the maturation of the neonatal immune system and gut epithelium as well as influencing microbial colonisation of the neonatal gut.

\section{Methods \\ Cows}

Three multiparous Holstein Friesian cows at the peak of their third or fourth lactation cycles and approximately 21 days post parturition were used. These cows had the following characteristics: Australian Breed Value (ABV) in the top 25\% ; lactation 5,500-9000 L/year; no history of clinical mastitis; SCCs < 200,000 cells/ml; and Johne's disease free. Each cow represented a different sire line and was fed and housed according to standard operating procedures at the Camden Campus, University of Sydney. None of the cows had any clinical signs of mastitis in any quarter prior to the experiment (i.e. no swelling, no overt signs of pain after prodding the udder, no redness, no clots in their milk, SCCs $<200,000$ cells/ml, no bacterial growth in milk samples). Animal experiments were performed in accordance with Australian Animal Ethics Guidelines and with approval from the Faculty of Veterinary Science Animal Ethics Committee, University of Syd- 


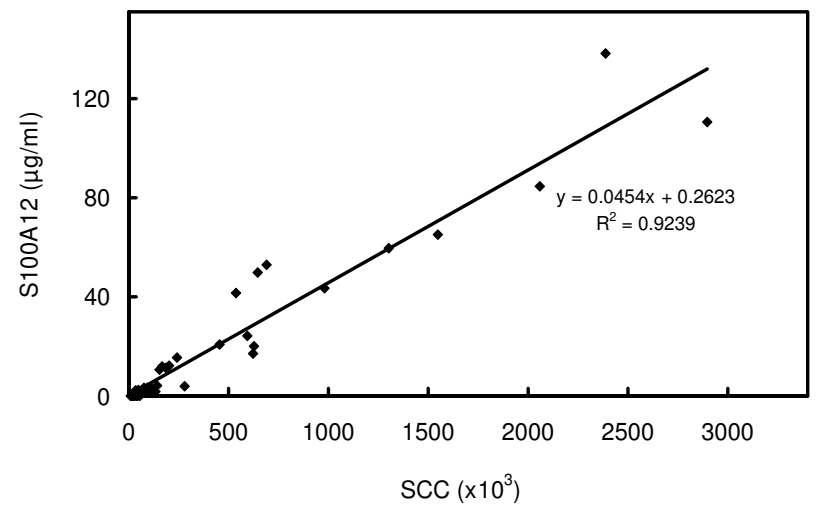

Figure 8

Correlation between the Somatic Cell Count (SCC) and SI OOA I 2 concentration in milk from dairy cattle. The plot shows the correlation between SI00AI2 concentration and SCC in milk from 38 dairy cows. The line of best fit drawn through the data has a correlation coefficient $\left(R^{2}\right)$ of 0.92 . The SCC was determined by flow cytometry of milk samples and the SIOOAI 2 levels in milk whey were determined using the SI00A I2-specific antigen capture ELISA with rSIOOAI 2 as the standard.

ney (N00/10-2003/2/3829: Collection of Mammary Biopsies for Dairy Cattle: the Induction of Mastitis).

\section{S. aureus strain}

An isolate of the virulent $S$. aureus strain, JG-80 [56], derived from a clinical case of ovine mastitis was grown overnight at $37^{\circ} \mathrm{C}$ in nutrient broth (BO0759Z; Oxoid) Bacteria were pelleted $\left(3,600 \times g, 4^{\circ} \mathrm{C}, 15 \mathrm{~min}\right)$ and washed in $20 \mathrm{ml}$ of pyrogen-free PBS $(\times 3)$. The bacterial concentration was estimated using the conversion ratio: $\mathrm{OD}_{600}$ of 0.46 equals $1 \times 10^{9}$ bacteria/ml [57]. Bacterial cultures were adjusted to the desired concentration by dilution in $5 \mathrm{ml}$ of pyrogen-free PBS.

\section{S. aureus intramammary challenge and mammary tissue collection}

The udders of the cows were determined to be free of bacteria by assaying a $10 \mathrm{ml}$ sample of milk from each quarter for bacterial growth, $24 \mathrm{~h}$ and $48 \mathrm{~h}$ prior to infusion with $S$. aureus. Despite the complete absence of any clinical symptoms and a SCC $<50,000$, one quarter of cow 1419 was found to have a low level $S$. aureus infection in the milk sample that was collected $24 \mathrm{~h}$ but not $48 \mathrm{~h}$ prior to the commencement of the experiment. As a consequence, this quarter was excluded from the experiment. Immediately following morning milking the udders were washed and disinfected. One quarter of the udder on each cow was infused with $5 \mathrm{ml}$ of pyrogen-free PBS (intra-animal control), while the other three quarters of each cow (except cow 1419) received a graded dose of $S$. aureus (5 $\times$
$10^{2}-1 \times 10^{6}$ bacteria) (Table 1 ). Infusions were delivered using a $4 \mathrm{~cm}$ infusion cannula inserted into the teat canal and then massaged further along the teat canal and into the udder tissue. The doses of bacteria were designed to produce low level subclinical mastitis (i.e. SCC > 200,000 cells $/ \mathrm{ml}$ ) within $16 \mathrm{~h}$ after which a second sample of milk $(10 \mathrm{ml})$ was collected for diagnostic analysis before the cows were euthanized. A 10-20 g sample of mammary tissue was then surgically removed from each udder quarter in less than $10 \mathrm{~min}$, snap frozen in three segments in liquid nitrogen and stored at $-80^{\circ} \mathrm{C}$. The secretory tissue samples were taken from carefully selected regions of each udder quarter avoiding large blood vessels and the cisternal region.

\section{Diagnostic analyses of milk samples}

Milk was collected according to a standard protocol [58] before and after pathogen infusion and sent for analysis to the Veterinary Pathology Diagnostic Services (University of Sydney). Standard procedures were used for assessment of bacterial content. The milk samples were assayed for bacterial growth and colony characteristics, and cultured bacteria were characterised using the Gram stain [59]. The bacterial culture was identified and tested for haemolytic, catalase and coagulase activities [60]. S. aureus was identified in cultures obtained from milk samples using the following criteria: growth and colony characteristics on Sheep Blood agar from Oxoid (Oxoid Australia Pty Ltd., Victoria); Gram positive stain; haemolytic on blood agar medium; catalase positive and coagulase positive. SCC was determined using laser based flow cytometry of the milk samples.

\section{Preparation of RNA}

Frozen mammary tissue ( $\sim \mathrm{g}$ ) was placed in liquid nitrogen, pulverised with a hammer, followed by addition of $25 \mathrm{ml}$ of Trizol reagent (Invitrogen). The tissue was homogenised using an Ultraturrax probe (IKA, 3 cycles of $2 \mathrm{~s})$ and RNA extracted according to the manufacturer's protocol (Invitrogen). RNA was further purified using an RNeasy Midi Kit (Qiagen) and each sample was treated twice with DNase I to eliminate contaminating genomic DNA. The purified RNA was quantified by spectrophotometric measurements and its purity and integrity verified by the $\mathrm{OD}_{260} / \mathrm{OD}_{280}$ ratio ( $>1.8$ ) and by visualisation on a denaturing gel. Controls without reverse transcriptase were also produced for qRT-PCR analyses to validate the absence of genomic DNA.

\section{Primer design and quantitative real time RT-PCR (qRT- PCR)}

All gene symbols are shown in italics when used in the context of the gene or mRNA but when used in the context of their encoded proteins they are denoted by normal text. Quantitative Real-Time Reverse Transcription PCR (qRT- 


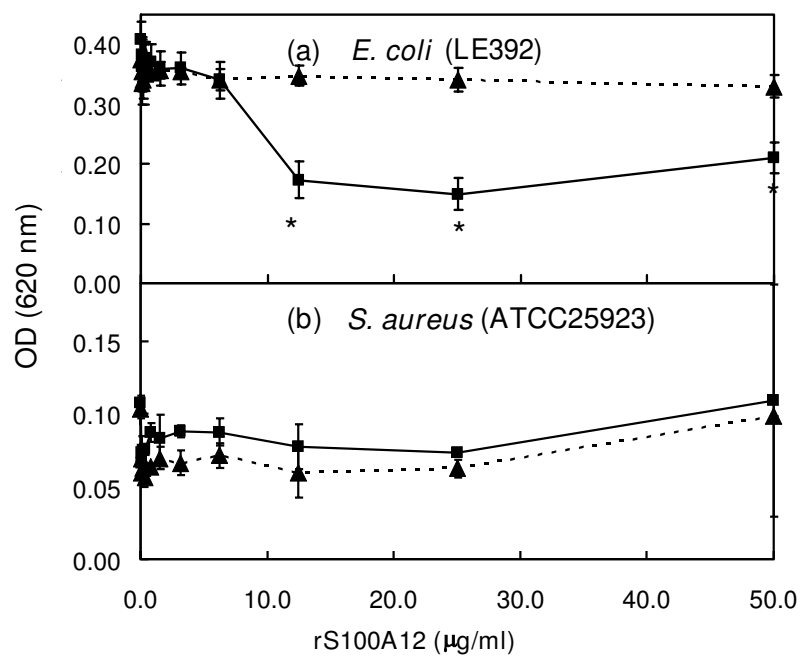

\section{Figure 9}

Antimicrobial activity of rS I00A I2. Antimicrobial activities of rSI00A 2 were measured using the Broth Microdilution Susceptibility Testing Method. (a) E. coli and (b) S. aureus. $(\square)$, rSI00A I2; (A) BSA at the same concentrations. Bars represent the means \pm SEM for 2 replicates. The data were examined for significance using ANOVA and the asterisk denotes significant differences $(P<0.05)$ from the control.

PCR) using the Sybr Green-based fluorescent detection system and the ABI Prism 7900 Sequence Detection System (PE Applied Biosystems, Forster City, CA), was used to measure mRNA abundance. Analysis of the data was performed using the Relative Expression Software Tool (REST), which generates a Mean Normalised Expression (MNE) value of a target transcript relative to a reference gene [61,62]. Primers were designed with the aid of MacVector (ver 7.1) (Accelrys) software and publicly available ovine and bovine sequences (Table 5). A constant amount of cDNA (10 ng) was used for qRT-PCR measurements. Four technical replicates were performed for each gene investigated. In addition, three independent cDNA samples were assessed for each tissue sample from each cow. This process allowed quantification of the target gene relative to a constant reference gene in each sample using threshold cycle $(\mathrm{Ct})$ data. Three potential reference genes, $18 S$ Ribosomal RNA (Genbank accession DQ222453), Glyceraldehyde 3-Phosphate Dehydrogenase (Genbank accession XM 868165) and Ribosomal Protein, large, P0 (RPLP0) (Genbank accession BT021080) were independently measured in all samples at constant cDNA input to determine which was the most suitable reference gene. This analysis revealed that the expression pattern of RPLPO showed least variation and therefore it was used as the reference gene.
Each qRT-PCR $(5 \mu \mathrm{l})$ contained: $2.5 \mu \mathrm{l}$ of $2 \times$ Sybr Green Master Mix (Applied Biosystems); $0.25 \mu \mathrm{l}$ of each primer giving a final concentration of $450 \mathrm{nM}$ each; $1.0 \mu$ l water; and $1.0 \mu \mathrm{l}$ of a $1 / 10$ dilution of the stock cDNA template. The reaction was started by heating $\left(95^{\circ} \mathrm{C}, 10 \mathrm{~min}\right)$ to activate the AmpliTaq Gold DNA polymerase. The cycling conditions consisted of 40 cycles of $95^{\circ} \mathrm{C}$ for $15 \mathrm{~s}$ and $60^{\circ} \mathrm{C}$ for $1 \mathrm{~min}$. All melt curves showed a single peak consistent with the presence of a single specific amplicon. Each qRT-PCR assay was validated by amplicon size and sequence. Amplification efficiency was independently measured for each amplicon [61]. Udder quarter differences in gene expression for each cow were analysed using One-way ANOVA and $\mathrm{P}<0.01$ was considered statistically significant.

\section{cDNA microarray transcript profiling}

The microarray experiments were performed using the Bovine Innate Immune Microarray platform [28]. The cDNA microarray comprises 1480 defined immune related genes in duplicate and 5327 anonymous cDNAs (in duplicate) from subtracted and normalised cDNA libraries derived from bovine peripheral blood lymphocytes (PBL), bovine mammary epithelial cells (MAC-T and bMEC) and bovine macrophages (BoMac), which underwent a variety of immune challenges. In addition, the microarray contains 384 control elements in quadruplicate and 49 orthologous ovine/bovine elements in quadruplicate. In some cases a single gene is represented by multiple elements. cDNA synthesis, labelling, microarray hybridisation and washing, and data acquisition were performed as previously described [28]. Data from each cow were separately analysed relative to their intramammary control as the initial qRT-PCR studies indicated that there was considerable variation in the magnitudes of individual cow responses for each tested gene. In the microarray analysis, gene expression in each quarter within a cow was directly compared to the gene expression in other quarters using an 'all pairs' design with reciprocal dye swaps i.e. in general, 12 microarrays were used per cow and 6 measurements were made of each sample. In this manner, each cow was initially independently analysed (Fig. 2). Data from these microarray experiments has been submitted to the Gene Expression Omnibus [63] (platform ID GPL6082, Series ID GSE9685).

\section{Microarray statistical analysis}

Statistical analysis of the microarray data was performed as previously described [28]. The mixed model used for the analysis of intensity expression signals accounted for $95.5 \%$ of the total variation. The main effect of probe and the interactions between probe by array, probe by dye and probe by dose accounted for $76.8 \%, 15.3 \%, 1.6 \%$ and $1.8 \%$, respectively. These proportions are consistent with previous studies applying mixed models to the analysis of 


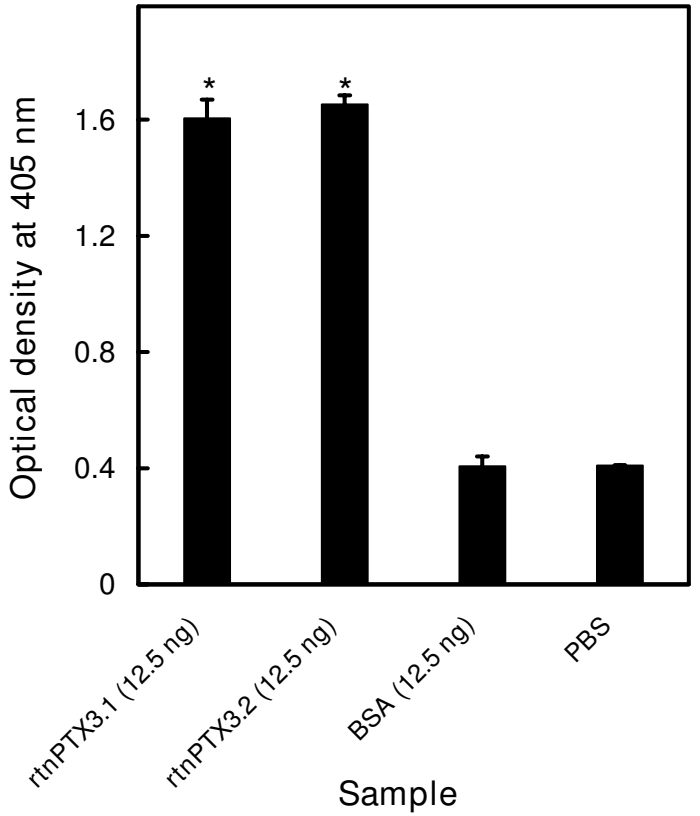

Figure 10

Binding of rtnPTX3 to immobilised human Clq. The binding of rtnPTX3 to immobilised human $\mathrm{Clq}$ was measured using an ELISA-based binding assay. The binding activities for two different preparations of rtnPTX3 (each I $2.5 \mathrm{ng} /$ well) are shown. The controls consisted of PBS and BSA ( $12.5 \mathrm{ng} /$ well). Significance was measured by ANOVA relative to the PBS control (*, P $<0.05)$.

expression data and anticipate that, for an optimal control of false discovery rate, approximately $1.8 \%$ of probes are expected to be found differentially expressed in any given contrast. The overall effects of $S$. aureus infection on mammary gene expression were visualised using GeneSpring 5.1 (Silicon Genetics, Redwood City, CA). The mean signal intensity for each significantly differentially expressed element, calculated using the statistical model described above, was loaded into the software. Differentially expressed elements, but limited to those with greater than 2 fold change in at least one sample and expression in all samples, were identified by analysis of samples from individual cows. The mean signal intensity for each treatment dose was calculated and these values were normalised to the mean signal intensity for the element in the intra-animal control sample. Thus, each differentially expressed element had a normalised mean signal intensity value for each $S$. aureus dose i.e. $500(n=1), 10,000(n=2)$, $100,000(n=3)$ or 1,000,000 $(n=2)$ bacteria, compared to the respective control samples. The reasons for the different number of biological samples with the different doses related to a different infection regime for one cow and the exclusion of one quarter in another cow from the experiment. The resulting profiles were subsequently clustered (K-means clustering) [30]. However, manual examination of these clusters in conjunction with the inherent redundancy on the microarray revealed that they required considerable consolidation. Consequently, the clusters were manually condensed into two primary groups i.e. a cluster of elements showing $S$. aureus-induced increased expression and a cluster of elements showing $S$. aureusinduced decreased expression.

\section{Sequencing of cDNA clones}

The Bovine Innate Immune Microarray comprised a significant number of elements derived from anonymous cDNA clones. The anonymous elements with expression profiles that were significantly altered by $S$. aureus infection were sequenced using standard protocols (Applied Biosystems, USA). The clipped EST sequences were submitted to the Genbank nucleotide sequence database with accession numbers EW739703-EW741108[64]. Annotations were added to the EST sequences by comparing them to the Genbank non-redundant and Human RefSeq nucleotide and amino acid databases using BLASTN and BLASTX $[65,66]$. Gene names were assigned to ESTs if the Expect score was less than $1 \times 10^{-10}$. The predicted biological functions of these genes were then determined through extensive PubMed literature searches for ortholog functions [64].

\section{Challenge of bMEC with LPS and LTA}

The culture and characterisation of the primary bovine mammary epithelial cells (bMEC) have been described elsewhere [12]. bMEC were grown in M199, Hams F12, $10 \mathrm{mM}$ Hepes, $20 \mathrm{mM} \mathrm{NaHCO}{ }_{3}, 2 \mathrm{mM} \mathrm{NaC}_{2} \mathrm{H}_{3} \mathrm{O}_{2}, 20 \%$ horse serum, 5\% FCS, $100 \mathrm{U} / \mathrm{ml}$ penicillin, $100 \mu \mathrm{g} / \mathrm{ml}$ streptomycin, $250 \mathrm{ng} / \mathrm{ml}$ amphotericin B, $100 \mathrm{ng} / \mathrm{ml} \mathrm{kan-}$ amycin (all reagents from Invitrogen Corporation Carlsbad, California), $5 \mu \mathrm{g} / \mathrm{ml}$ insulin, $1 \mu \mathrm{g} / \mathrm{ml}$ cortisol (Sigma Chemical Co., St Louis), $10 \mathrm{ng} / \mathrm{ml}$ EGF (MP Biomedicals, Irvine, CA), $\mathrm{pH}$ 7.4. bMEC were seeded at $4 \times$ $10^{4}$ cells per well in 6 well plates (Sarstedt) and grown until $80 \%$ confluence at $37^{\circ} \mathrm{C}$, then challenged with LPS $(50 \mu \mathrm{g} / \mathrm{ml})$ or LTA $(20 \mu \mathrm{g} / \mathrm{ml})$ for $0,2,4,8,16$ and $24 \mathrm{~h}$. The concentrations of LTA and LPS used with the bMEC were determined from titration analyses [12]. LPS was purchased as a lyophilised powder purified from E. coli strain 055:B5 by phenol extraction (Sigma Chemical Co.) [67]. LTA isolated from Streptococcus pyogenes was obtained from Sigma Chemical Co [68].

\section{Cloning, expression and purification of rSI00A I 2 and rPTX3}

The nucleotide sequence encoding bovine PTX3, without the region encoding the signal sequence, was cloned into 


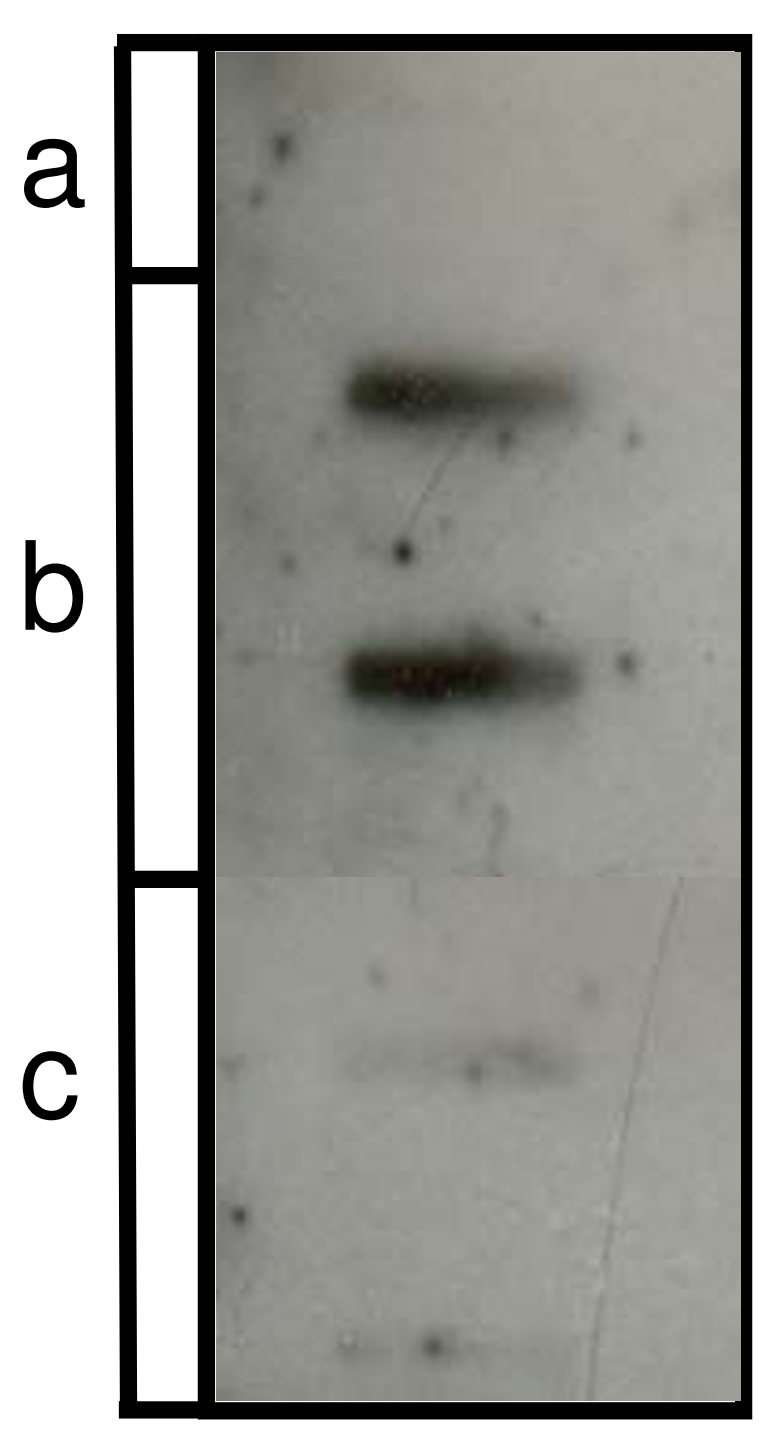

Figure I I

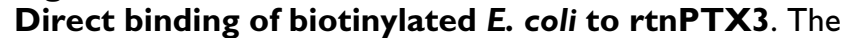
binding of biotinylated $E$. coli (ATCC 352I8) to rtnPTX3 immobilised onto a nitro-cellulose membrane was measured. (a) PBS; (b) rPTX3 in duplicate $(50 \mu \mathrm{g})$; and (c) BSA, in duplicate $(50 \mu \mathrm{g})$.

the bacterial expression vector pQE9 (Qiagen) and expressed and purified according to the manufacturer's instructions (primer sequences are listed in Table 5). rPTX3 was identified by size, N-terminal sequence and its reactivity with the Ni-NTA affinity resin and Ni-NTA HRP conjugate. The protein was refolded [69] and dialysed into $50 \mathrm{mM}$ Tris- $\mathrm{HCl} \mathrm{pH} 8,500 \mathrm{mM} \mathrm{NaCl}$ and $20 \%$ glycerol.

The nucleotide sequence encoding bovine S100A12 was cloned into the bacterial expression vector pQE9 (Qiagen)
(Table 5) and expressed as per the manufacturer's instructions. The recombinant protein (rS100A12) was expressed in the cytoplasm and purified using Ni-NTA affinity chromatography (Qiagen). All buffers contained Complete EDTA-free protease inhibitors (Roche Applied Science). Protein quantities were determined using the BCA Protein Assay kit (Pierce) with BSA as the standard. Endotoxin levels in the recombinant proteins were less than $0.05 \mathrm{EU} / \mathrm{ml}$ using the Cambrex Limulus Amebocyte Lysate (LAL) pyro Plus Gel Cot assay (lonza, Basel, Switzerland)

N-terminal amino acid sequencing of rS I OOA I 2 and rPTX3 Purified rPTX3 and rS100A12 were blotted onto polyvinylidine fluoride (PVDF) membrane (Problot, Applied Biosystems) and their $\mathrm{N}$-terminal amino acid sequences were determined using a Procise Protein Sequencer (Applied Biosystems). The sequences confirmed the expected N-terminal sequences (underlined) i.e. MRGSHHHHHHGS ENSDDY(rPTX3); MRGSHHHHHHGS TKLEDHLE(rS100A12).

\section{Production of polyclonal antibodies and development of SIOOAI 2 and PTX3-specific enzyme-linked immunosorbent assays (ELISAs)}

Four aliquots, each of $50 \mu \mathrm{g}$ of purified rPTX3 (in $6 \mathrm{M}$ urea), and four aliquots, each of $250 \mu \mathrm{g}$ of purified S100A12 (in PBS), were used for the production of rabbit polyclonal antibodies (Institute of Medical and Veterinary Science Polyclonal Antibody Production, Gilles Plains, South Australia). Each rabbit was injected with one aliquot of antigen (with adjuvant) 4 times at 3 week intervals. Serum samples were collected from the rabbits 2 weeks after the last injection. Antibodies to rPTX3 and rS100A12 were immunoaffinity purified [69]. Antigen-specific capture ELISAs were used to measure the concentrations of endogenous S100A12 and PTX3 in milk whey samples. The antigen capture ELISAs used the immuno-affinity purified antibodies (500 ng/well and $100 \mathrm{ng} /$ well for S100A12 and PTX3, respectively) as capture antibodies and biotinylated forms of the same antibodies $(1 \mu \mathrm{g} / \mathrm{ml})$ for detection $[69,70]$. The biotinylated antibodies were detected with HRP-streptavidin-biotin complex (Amersham Life Science, UK) (1/500 in PBS). Milk samples were centrifuged $\left(2,500 \times g, 20 \mathrm{~min}, 4^{\circ} \mathrm{C}\right)$, the cream layer removed, recentrifuged $\left(100,000 \times g, 4^{\circ} \mathrm{C}, 30 \mathrm{~min}\right)$ and filtered $(0.45 \mu \mathrm{m}$ filter). Milk whey was diluted 1 in 5 with PBS for S100A12 and 1 in 2 for PTX3 detections and 100 $\mu \mathrm{l}$ added after coating the plate with the primary affinity purified antibody. The concentrations of S100A12 and PTX3 in milk whey were calculated from standard curves.

The S100A12-specific antigen capture ELISA was also used to measure the concentrations of S100A12 in milk whey samples obtained from 38 dairy cows (Corstorphine Dairy, Camden NSW, Australia). The milk samples were 
stored in $30 \mathrm{ml}$ herd recording tubes, each pre-loaded with the milk preservative bromopol, and stored at $4{ }^{\circ} \mathrm{C}$. The somatic cells in the milk samples were measured using laser based flow cell cytometry with a Bentley Somacount 300 (Bentley Instruments Inc., Minnesota, USA) [71]. Samples were warmed to $40^{\circ} \mathrm{C}$ prior to SCC analysis to ensure all fat was mixed back in the sample.

\section{SDS-PAGE and immunoblots}

The conditions used for SDS-PAGE and immunoblotting have been described elsewhere [72]. Unless specified, all samples were run under reducing conditions. Immunoaffinity purified antibodies to rS100A12 and rPTX3 were used in the immunoblots at final concentrations of 1 and $0.5 \mu \mathrm{g} / \mathrm{ml}$, respectively. The same concentration of purified rabbit antibodies from pre-vaccination serum did not recognise either of the recombinant proteins in control immunoblots.

\section{Cloning, expression and purification of recombinant PTX3 expressed in insect cells}

The cDNA encoding the mature PTX3 polypeptide was cloned into the insect cell expression vector PIEx5 (Novagen) (Table 5). The vector encodes the signal peptide of adipokinetic hormone thus potentially resulting in secretion of the recombinant protein into the culture medium. The plasmid was transformed into XL1-Blue cells and purified using an Endo-free Maxi plasmid kit (Qiagen). Trichoplusia ni insect cells (Protein Expression Facility, University of Queensland) were grown in serum-free Sf900-II ${ }^{\oplus}$ medium (GIBCO) $\left(1.1 \times 10^{6}\right.$ cells $\left./ \mathrm{ml}\right)$ and transiently transfected using $800 \mu \mathrm{l}$ of Insect GeneJuice ${ }^{\circledast}$ transfection reagent (Novagen) and $150 \mu \mathrm{g}$ of endotoxin-free plasmid for each $100 \mathrm{ml}$ of cells [73]. Cells were grown at $28^{\circ} \mathrm{C}(120 \mathrm{rpm} ; 48 \mathrm{~h})$ at and the culture medium contain- ing secreted recombinant PTX3 (rtnPTX3) was harvested $(400 \times g, 10 \mathrm{~min})$. The medium was filtered, concentrated and dialysed into $20 \mathrm{mM}$ Tris-HCl, pH 8.0, $1 \mathrm{mM}$ EDTA, $5 \mathrm{mM}$ benzamidine. The rtnPTX3 was then purified using anion exchange chromatography (Q-Sepharose).

\section{Reduction and alkylation of rtnPTX3}

Purified rtnPTX3 or rPTX3 (each $100 \mu \mathrm{g}$ in $100 \mu \mathrm{l}$ ) were mixed with an equal volume of $8 \mathrm{M}$ urea in $20 \mathrm{mM}$ Tris$\mathrm{HCl}, \mathrm{pH} 8.0$ to denature the protein. Dithiothreitol $(15 \mu \mathrm{l}$ of $45 \mathrm{mM}$ ) was added and incubated at $50^{\circ} \mathrm{C}$ for $15 \mathrm{~min}$. Freshly prepared iodoacetamide $(16.5 \mu \mathrm{l}$ of $100 \mathrm{mM})$ was subsequently added to the reduced samples which were incubated in the dark at RT for $45 \mathrm{~min}$.

\section{Bacterial growth inhibition}

Assays to measure inhibition of bacterial growth were performed using the Broth Micro-dilution Susceptibility Testing Method [45]. A frozen stationary culture of E. coli (LE392) was streaked onto LB agar plates and a single colony was subcultured in $6 \mathrm{ml}$ of Muller-Hinton broth and incubated at $37^{\circ} \mathrm{C}(200 \mathrm{rpm}, 5 \mathrm{~h})$. Mid-logarithmic growth phase bacteria were diluted 1:250 in TBS, pH 7.2. Two fold serial dilutions of rS100A12 and the controls (antibiotics or BSA) were prepared in sterile polypropylene plates (Nunc, Roskilde, Denmark) compatible with cationic peptides. Purified rS100A12 $(50 \mu \mathrm{g} / \mathrm{ml})$, control antibiotics $(25 \mu \mathrm{g} / \mathrm{ml}$ ampicillin and $12.5 \mu \mathrm{g} / \mathrm{ml}$ kanamycin) and BSA $(80 \mu \mathrm{g} / \mathrm{ml})$ in TBS pH 7.2 were used in the assays. Each plate also included wells containing the bacterial inoculum without any additives. Plates containing $10 \mu \mathrm{l}$ of the diluted test compounds, $100 \mu \mathrm{l}$ of $2 \times$ MullerHinton broth and $80 \mu \mathrm{l}$ of water were then inoculated with $10 \mu \mathrm{l}$ of diluted cultures $\left(1 \times 10^{5} \mathrm{cfu} / \mathrm{ml}\right)$ in a final volume of $200 \mu \mathrm{l}$ of $1 \times$ strength Muller-Hinton broth and

Table 5: Oligonucleotide primer sequences used for qRT-PCR and recombinant protein expression

\begin{tabular}{|c|c|c|c|c|c|}
\hline Gene & Accession number & Forward $\left(5^{\prime} \rightarrow 3^{\prime}\right)$ & Reverse $\left(5^{\prime} \rightarrow 3^{\prime}\right)$ & Size (bp) & Ref. \\
\hline RPLPO & BT021080 & CAACCCTGAAGTGCTTGACAT & AGGCAGATGGATCAGCCA & 220 & {$[12]$} \\
\hline$I L-I \beta$ & M35589 & AAATGAACCGAGAAGTGGTGTT & TTCCATATTCCTCTTGGGGTAGA & 185 & {$[12]$} \\
\hline IL-6 & $\underline{\mathrm{X57317}}$ & CTGGGTTCAATCAGGCGAT & CAGCAGGTCAGTGTTTGTGG & 206 & [12] \\
\hline IL-8 & AF232704 & CTGTGTGAAGCTGCAGTTCT & TAAGCAGACCTCGTTTCCAT & 180 & {$[12]$} \\
\hline$T N F \alpha$ & NM 173966 & CTGGTTCAGACACTCAGGTCCT & GAGGTAAAGCCCGTCAGCA & 183 & {$[12]$} \\
\hline$C D / 4$ & D84509 & GGTGCTACCCGATGTGTCTG & AAGGGATTTCCGTCCAGAGT & 191 & {$[12]$} \\
\hline CSNISI & M3864I & СCTGTCTTGTGGCTGTTGCTCTTG & САTCTTCCTTTTGAATGTGCTTCTGCT & 282 & pc* \\
\hline CSN2 & $\underline{M 16645}$ & TCTGCCTCTGCTCCAGTCTT & AGGAGGGGGCATTCACTTT & 251 & $\mathrm{pc}^{*}$ \\
\hline$S / 00 A / 2$ & NM 17465I & CATTTCGACACCCTCAACAA & CTGTTTTCAGCACCCTGGAC & 184 & \\
\hline rSIOOAI2 & $\underline{N M} 174651$ & $\begin{array}{l}\text { CCGGATCCACTAAGCTGGAAGATCAC } \\
\text { CTGGAGG }\end{array}$ & $\begin{array}{l}\text { CCAAGCTTTACTCTTTGTGGATATCT } \\
\text { ATGTGGGCTG }\end{array}$ & - & \\
\hline PTX3 & NM 001076259 & TATGCCATGGTGCTTTCAGA & CCAATGAACAATGGACAACAA & 182 & \\
\hline rPTX3 & NM 001076259 & $\begin{array}{l}\text { ATGGATCCGAGAACTCAGATGATTATG } \\
\text { AGCTCATGTA }\end{array}$ & $\begin{array}{l}\text { AGAAGCTTTTAATAAACATACTGTGC } \\
\text { TCCTCGTG }\end{array}$ & - & \\
\hline rtnPTX3 & NM 001076259 & $\begin{array}{l}\text { GTGGATCCGGAGAACTCAGATGATTAT } \\
\text { GAGCTCATGTA }\end{array}$ & $\begin{array}{l}\text { AGAAGCTTTTTAATAAACATACTGTGC } \\
\text { TCCTCGTG }\end{array}$ & - & \\
\hline
\end{tabular}

* Personal communication (Karen Matthews) 
incubated for $24 \mathrm{~h}$. The plates were examined after $16 \mathrm{~h}$ and bacterial cell growth assessed by measuring the optical density at $620 \mathrm{~nm}$ (Spectramax Plus microplate reader, Molecular Devices, Sunnyvale, CA, USA).

\section{Binding of rtnPTX3 to bacteria}

Colonies of low pathogenicity strains of $S$. aureus (ATCC 25923) [74] or E. coli (ATCC 35218) were grown in $50 \mathrm{ml}$ Falcon tubes containing $20 \mathrm{ml}$ LB Broth $\left(37^{\circ} \mathrm{C}, 16 \mathrm{~h}, 200\right.$ $\mathrm{rpm})$. The bacterial cultures were pelleted $(3,000 \times g)$, washed in PBS, pH 8.0 and diluted to an $\mathrm{OD}^{600} \mathrm{~nm}$ of 0.8 $\left(2.5 \times 10^{9}\right.$ bacteria/ml $) .25 \mathrm{ml}$ of each bacterial sample was subsequently mixed with $25 \mathrm{mg}$ of Sulfo-NHS-LCBiotin (Pierce) according to the manufacturer's recommendations. Unbound biotin was removed by 3 washes with PBS and the pellets resuspended in $25 \mathrm{ml}$ of PBS, $\mathrm{pH}$ 8.0. rtnPTX3 $(50 \mu \mathrm{g})$ was immobilised onto HyBond C nitrocellulose (GE Healthcare Life Sciences) using a BioDot $^{\circledR}$ SF Microfiltration Apparatus (BioRad). The negative controls were PBS or BSA. The membranes were then blocked using $5 \%$ BSA in TBS $(0.05 \%$ Tween), washed and incubated overnight with $2 \times 10^{9}$ biotinylated bacteria (in $25 \mathrm{ml}$ ) with gentle rocking at $4^{\circ} \mathrm{C}$. The membranes were then washed and incubated with HRP-StreptavidinBiotin complex (1:500) in TBS for $2 \mathrm{~h}$ (RT), followed by three washes with TBS. Colour was developed using enhanced chemiluminescence (Pierce ECL Western Blotting Substrate).

\section{Binding of rtnPTX3 to human $\mathrm{Clq}$}

Binding of rtnPTX3 to human C1q was examined as previously described $[43,46]$. Briefly, 96-well plates were coated with $500 \mathrm{ng}$ of human C1q (Merck) in $100 \mu \mathrm{l}$ of PBS, pH 7.4 with $1 \mathrm{mM} \mathrm{CaCl}_{2}$ and $1 \mathrm{mM} \mathrm{MgCl}_{2}\left(4^{\circ} \mathrm{C}\right.$, ON). Wells were washed with PBS plus $0.05 \%$ Tween 20 , blocked with $0.5 \%$ milk powder in PBS-Tween $20(2 \mathrm{~h}$ at RT) before addition of $100 \mu \mathrm{l}$ of different preparations of rtnPTX3 (each $12.5 \mathrm{ng}$ ) in PBS-Tween $20\left(1 \mathrm{~h}\right.$ at $\left.37^{\circ} \mathrm{C}\right)$. The wells were washed in PBS-Tween 20 and incubated with $1 \mu \mathrm{g} / \mathrm{ml}$ of the immunoaffinity purified rabbit antibody raised to rPTX3 $\left(1 \mathrm{~h}\right.$ at $\left.37^{\circ} \mathrm{C}\right)$, washed again and incubated with $1 \mu \mathrm{g} / \mathrm{ml}$ of HRP-conjugated anti-rabbit $\operatorname{IgG}\left(1 \mathrm{~h}\right.$ at $\left.37^{\circ} \mathrm{C}\right)$. After further washing, $200 \mu \mathrm{l}$ of 2,2'azino-bis (3- ethylbenzthiazoline-6-sulfonic acid) was added for $20 \mathrm{~min}$. The reaction was stopped by addition of $50 \mu \mathrm{l}$ of $4 \%$ SDS and absorbance at $405 \mathrm{~nm}$ measured.

\section{Authors' contributions}

CPG and TV were responsible for the experimental $S$. aureus challenge of cows and sample collection. PAS aided the identification of cows and collection of samples while RW assisted with the design of the challenge experiment. AR performed the statistical analyses of the microarray data. LD performed the microarray analysis while YCSL, TV and CPG undertook the GRT-PCR analyses. LD expressed rS100A12 and YCSL expressed rPTX3 in bacteria. YCSL performed the S100A12 and PTX3 immunoblots and the PTX3 ELISAs. YCSL, KAB and LD carried out the S100A12 ELISAs. KAB performed the anti-bacterial assays with rS100A12. YCSL expressed and purified rtnPTX3 in insect cells. RDP assisted with the purification of recombinant proteins and polyclonal antibodies and performed the $\mathrm{N}$-terminal sequencing of the recombinant proteins. RLT conceived the study, and participated in its design, coordination, analysis and manuscript writing. All authors read and approved the final manuscript

\section{Acknowledgements}

We thank Rob Moore (CSIRO Livestock Industries, Geelong) for printing the Bovine Innate Immune Microarray and lan Colditz (CSIRO Livestock Industries, Armidale) for valuable discussions. We would also like to thank Nicole Spiegel for collecting the Camden milk samples and Sean McWilliam for assisting with sequence analyses. This research was supported by the Co-operative Research Centre for Innovative Dairy Products.

\section{References}

I. De Oliveira AP, Watts JL, Salmon SA, Aarestrup FM: Antimicrobial susceptibility of Staphylococcus aureus isolated from bovine mastitis in Europe and the United States. J Dairy Sci 2000, 83(4):855-862.

2. Sordillo LM, Streicher KL: Mammary gland immunity and mastitis susceptibility. J Mammary Gland Biol Neoplasia 2002. 7(2): 135-146.

3. Fox LK, Gay JM: Contagious mastitis. Vet Clin North Am Food Anim Pract 1993, 9(3):475-487.

4. Sutra L, Poutrel B: Virulence factors involved in the pathogenesis of bovine intramammary infections due to Staphylococcus aureus. J Med Microbiol 1994, 40(2):79-89.

5. Almeida RA, Matthews KR, Cifrian E, Guidry AJ, Oliver SP: Staphylococcus aureus invasion of bovine mammary epithelial cells. J Dairy Sci 1996, 79(6): 1021-1026.

6. Hamill RJ, Vann JM, Proctor RA: Phagocytosis of Staphylococcus aureus by cultured bovine aortic endothelial cells: model for postadherence events in endovascular infections. Infect Immun 1986, 54(3):833-836.

7. Vann JM, Proctor RA: Ingestion of Staphylococcus aureus by bovine endothelial cells results in time- and inoculumdependent damage to endothelial cell monolayers. Infect Immun 1987, 55(9):2।55-2163.

8. Burton JL, Erskine RJ: Immunity and mastitis. Some new ideas for an old disease. Vet Clin North Am Food Anim Pract 2003, 19(I): I-45.

9. Rainard $P$, Riollet $C$ : Mobilization of neutrophils and defense of the bovine mammary gland. Reprod Nutr Dev 2003, 43(5):439-457.

10. Boutet $P$, Boulanger D, Gillet $L$, Vanderplasschen A, Closset $R$, Bureau F, Lekeux $P$ : Delayed neutrophil apoptosis in bovine subclinical mastitis. J Dairy Sci 2004, 87( I 2):4 I04-4I I4.

II. Alluwaimi AM, Leutenegger CM, Farver TB, Rossitto PV, Smith WL, Cullor JS: The cytokine markers in Staphylococcus aureus mastitis of bovine mammary gland. J Vet Med B Infect Dis Vet Public Health 2003, 50(3): 105-III.

12. Strandberg Y, Gray C, Vuocolo T, Donaldson L, Broadway M, Tellam $\mathrm{R}$ : Lipopolysaccharide and lipoteichoic acid induce different innate immune responses in bovine mammary epithelial cells. Cytokine 2005, 3I(I):72-86.

13. Okada H, Ito T, Ohtsuka H, Kirisawa R, Iwai H, Yamashita K, Yoshino T, Rosol T]: Detection of interleukin-I and interleukin-6 on cryopreserved bovine mammary epithelial cells in vitro. J Vet Med Sci 1997, 59(7):503-507.

14. Lahouassa $\mathrm{H}$, Moussay E, Rainard P, Riollet $\mathrm{C}$ : Differential cytokine and chemokine responses of bovine mammary epithelial cells to Staphylococcus aureus and Escherichia coli. Cytokine 2007, 38(I):|2-2|. 
15. Madsen SA, Chang LC, Hickey MC, Rosa G], Coussens PM, Burton JL: Microarray analysis of gene expression in blood neutrophils of parturient cows. Physiol Genomics 2004, 16(2):2 12-22I.

16. Burton JL, Madsen SA, Yao J, Sipkovsky SS, Coussens PM: An immunogenomics approach to understanding periparturient immunosuppression and mastitis susceptibility in dairy cows. Acta Vet Scand 200I, 42(3):407-424

17. Lee JW, Bannerman DD, Paape MJ, Huang MK, Zhao X: Characterization of cytokine expression in milk somatic cells during intramammary infections with Escherichia coli or Staphylococcus aureus by real-time PCR. Vet Res 2006, 37(2):219-229.

18. Schmitz S, Pfaffl MW, Meyer HH, Bruckmaier RM: Short-term changes of mRNA expression of various inflammatory factors and milk proteins in mammary tissue during LPSinduced mastitis. Domest Anim Endocrinol 2004, 26(2): I I - I 26.

19. Bannerman DD, Chockalingam A, Paape MJ, Hope JC: The bovine innate immune response during experimentally-induced Pseudomonas aeruginosa mastitis. Vet Immunol Immunopathol 2005, 107(3-4):201-2।5.

20. Bannerman DD, Paape MJ, Hare WR, Hope JC: Characterization of the bovine innate immune response to intramammary infection with Klebsiella pneumoniae. J Dairy Sci 2004, 87(8):2420-2432.

21. Rambeaud M, Almeida RA, Pighetti GM, Oliver SP: Dynamics of leukocytes and cytokines during experimentally induced Streptococcus uberis mastitis. Vet Immunol Immunopathol 2003, 96(34): 193-205.

22. Pareek R, Wellnitz O, Van Dorp R, Burton J, Kerr D: Immunorelevant gene expression in LPS-challenged bovine mammary epithelial cells. J Appl Genet 2005, 46(2): I7I-I77.

23. Boudjellab N, Chan-Tang HS, Zhao X: Bovine interleukinexpression by cultured mammary epithelial cells (MAC-T) and its involvement in the release of MAC-T derived interleukin-8. Comp Biochem Physiol A Mol Integr Physiol 2000, I27(2): 191-199.

24. Wever P, Emanuelson U: Effects of systematic influences and intramammary infection on differential and total somatic cell counts in quarter milk samples from dairy cows. Acta Vet Scand 1989, 30(4):465-474.

25. Mehrzad J, Dosogne H, Meyer E, Burvenich C: Local and systemic effects of endotoxin mastitis on the chemiluminescence of milk and blood neutrophils in dairy cows. Vet Res 200I, 32(2): $|3|-\mid 44$.

26. Silva LF, Liesman JS, Etchebarne BE, Nielsen MS, Vandehaar MJ: Short communication: intramammary infusion of IGF-I increases bromodeoxyuridine labeling in mammary epithelial cells of prepubertal heifers. J Dairy Sci 2005, 88(8):277|-2773.

27. Bannerman DD, Paape MJ, Goff JP, Kimura K, Lippolis JD, Hope JC: Innate immune response to intramammary infection with Serratia marcescens and Streptococcus uberis. Vet Res 2004, 35(6):68I-700.

28. Donaldson L, Vuocolo T, Gray C, Strandberg Y, Reverter A, McWilliam S, Wang Y, Byrne K, Tellam R: Construction and validation of a Bovine Innate Immune Microarray. BMC Genomics 2005 , 6:135.

29. Benjamini $\mathrm{YaH}, \mathrm{Y}$ : "Controlling the false discovery rate: A practical and powerful approach to multiple testing.". Journal of the Royal Statistical Society B 1995, 57:289-300.

30. Hartigan J, Wang M: A K-means clustering algorithm. Applied Statistics 1979, 28:100-108.

31. Jaillon S, Peri G, Delneste Y, Fremaux I, Doni A, Moalli F, Garlanda C, Romani L, Gascan H, Bellocchio S, et al.: The humoral pattern recognition receptor $P T X 3$ is stored in neutrophil granules and localizes in extracellular traps. J Exp Med 2007, 204(4):793-804.

32. Hofmann MA, Drury S, Fu C, Qu W, Taguchi A, Lu Y, Avila C, Kambham N, Bierhaus A, Nawroth P, et al.: RAGE mediates a novel proinflammatory axis: a central cell surface receptor for S100/calgranulin polypeptides. Cell 1999, 97(7):889-90I.

33. Klok MD, Jakobsdottir S, Drent ML: The role of leptin and ghrelin in the regulation of food intake and body weight in humans: a review. Obes Rev 2007, 8(I):2I-34.

34. Palsson-McDermott EM, O'Neill LA: Signal transduction by the lipopolysaccharide receptor, Toll-like receptor-4. Immunology 2004, I I3(2): 153-162.

35. Aderem A, Ulevitch RJ: Toll-like receptors in the induction of the innate immune response. Nature 2000, 406(6797):782-787.
36. O'Neill LA, Dunne A, Edjeback M, Gray P, Jefferies C, Wietek C: Mal and MyD88: adapter proteins involved in signal transduction by Toll-like receptors. J Endotoxin Res 2003, 9(1):55-59.

37. Guha M, Mackman N: LPS induction of gene expression in human monocytes. Cell Signal 200I, I3(2):85-94

38. Minty A, Chalon P, Derocq JM, Dumont X, Guillemot JC, Kaghad M, Labit C, Leplatois P, Liauzun P, Miloux B, et al.: Interleukin- $\mathbf{3}$ is a new human lymphokine regulating inflammatory and immune responses. Nature 1993, 362(6417):248-250.

39. McKenzie AN, Culpepper JA, de Waal Malefyt R, Briere F, Punnonen J, Aversa G, Sato A, Dang W, Cocks BG, Menon S, et al:: Interleukin 13, a T-cell-derived cytokine that regulates human monocyte and B-cell function. Proc Natl Acad Sci USA 1993, 90(8):3735-3739.

40. Norata GD, Ongari M, Garlaschelli K, Raselli S, Grigore L, Catapano $\mathrm{AL}$ : Plasma resistin levels correlate with determinants of the metabolic syndrome. Eur J Endocrinol 2007, I 56(2):279-284.

4I. Kusminski CM, da Silva NF, Creely SJ, Fisher FM, Harte AL, Baker AR, Kumar S, McTernan PG: The in vitro effects of resistin on the innate immune signaling pathway in isolated human subcutaneous adipocytes. J Clin Endocrinol Metab 2007, 92(I):270-276.

42. Moroz OV, Dodson GG, Wilson KS, Lukanidin E, Bronstein IB: Multiple structural states of SIO0AI2: A key to its functional diversity. Microsc Res Tech 2003, 60(6):58I-592.

43. Bottazzi B, Vouret-Craviari V, Bastone A, De Gioia L, Matteucci C, Peri G, Spreafico F, Pausa M, D'Ettorre C, Gianazza E, et al:: Multimer formation and ligand recognition by the long pentraxin PTX3. Similarities and differences with the short pentraxins $C$-reactive protein and serum amyloid $\mathbf{P}$ component. J Biol Chem 1997, 272(52):32817-32823.

44. Cole AM, Kim YH, Tahk S, Hong T, Weis P, Waring AJ, Ganz T: Calcitermin, a novel antimicrobial peptide isolated from human airway secretions. FEBS Lett 200I, 504(I-2):5-10.

45. Cudic M, Condie BA, Weiner DJ, Lysenko ES, Xiang ZQ, Insug O, Bulet $P$, Otvos $L$ Jr: Development of novel antibacterial peptides that kill resistant isolates. Peptides 2002, 23( I 2):207|-2083.

46. Rivieccio V, Esposito A, Bellofiore P, Palladino P, Sassano M, Colombo $M$, Verdoliva A: High-level expression and efficient purification of recombinant human long pentraxin PTX3 in Chinese hamster ovary cells. Protein Expr Purif 2007, 5 I (I):49-58

47. Garlanda C, Hirsch E, Bozza S, Salustri A, De Acetis M, Nota R, Maccagno A, Riva F, Bottazzi B, Peri G, et al.: Non-redundant role of the long pentraxin $P T X 3$ in anti-fungal innate immune response. Nature 2002, 420(69/2): $182-186$

48. Riollet C, Rainard P, Poutrel B: Differential induction of complement fragment $\mathrm{C5a}$ and inflammatory cytokines during intramammary infections with Escherichia coli and Staphylococcus aureus. Clin Diagn Lab Immunol 2000, 7(2): 161-167.

49. Bannerman DD, Paape MJ, Lee JW, Zhao X, Hope JC, Rainard P. Escherichia coli and Staphylococcus aureus elicit differential innate immune responses following intramammary infection. Clin Diagn Lab Immunol 2004, I I(3):463-472.

50. Lahouassa H, Moussay E, Rainard P, Riollet C: Differential cytokine and chemokine responses of bovine mammary epithelial cells to Staphylococcus aureus and Escherichia coli. Cytokine 2007.

5I. Yang Z, Tao T, Raftery MJ, Youssef P, Di Girolamo N, Geczy CL: Proinflammatory properties of the human $\mathrm{S} 100$ protein SI 00AI 2. J Leukoc Biol 200I, 69(6):986-994.

52. Breviario F, d'Aniello EM, Golay J, Peri G, Bottazzi B, Bairoch A, Saccone S, Marzella R, Predazzi V, Rocchi M, et al.: Interleukin-I-inducible genes in endothelial cells. Cloning of a new gene related to $\mathbf{C}$-reactive protein and serum amyloid $\mathbf{P}$ component. J Biol Chem 1992, 267(31):22190-22197.

53. Hatakeyama T, Okada M, Shimamoto S, Kubota Y, Kobayashi R: Identification of intracellular target proteins of the calcium-signaling protein SI O0A I 2. Eur J Biochem 2004, 27 I ( I8):3765-3775.

54. Schmidt AM, Yan SD, Yan SF, Stern DM: The multiligand receptor RAGE as a progression factor amplifying immune and inflammatory responses. J Clin Invest 200 I, 108(7):949-955.

55. Rainard P, Riollet C: Innate immunity of the bovine mammary gland. Vet Res 2006, 37(3):369-400.

56. Kerlin RL, Watson DL: Variations in immunoglobulin isotype produced during the antibody response to Brucella abortus 
and Staphylococcus aureus vaccines in sheep. Res Vet Sci 1986, 4I(2): I9I-I95.

57. Hirsch JG, Strauss B: Studies on Heat-Labile Opsonin in Rabbit Serum. J Immunol I964, 92: |45-I54.

58. Alluwaimi AM: The cytokines of bovine mammary gland: prospects for diagnosis and therapy. Res Vet Sci 2004, 77(3):2 I I-222.

59. Bartholomew JW, Mittwer T: The Gram stain. Bacteriol Rev 1952, 16(1): I-29.

60. Schukken YH, Leslie KE, Barnum DA, Mallard BA, Lumsden JH, Dick PC, Vessie GH, Kehrli ME: Experimental Staphylococcus aureus intramammary challenge in late lactation dairy cows: quarter and cow effects determining the probability of infection. J Dairy Sci I999, 82(I I):2393-240I.

61. Pfaff MW: A new mathematical model for relative quantification in real-time RT-PCR. Nucleic Acids Res 200I, 29(9):e45.

62. Pfaffl MW, Horgan GW, Dempfle L: Relative expression software tool (REST) for group-wise comparison and statistical analysis of relative expression results in real-time PCR. Nucleic Acids Res 2002, 30(9):e36.

63. Gene Expression Omnibus [http://www.ncbi.nlm.nih.gov/geo]

64. National Center for Biotechnology Information [http:// www.ncbi.nlm.nih.gov]

65. Benson DA, Karsch-Mizrachi I, Lipman DJ, Ostell J, Wheeler DL GenBank: update. Nucleic Acids Res 2004:D23-26.

66. Altschul SF, Madden TL, Schaffer AA, Zhang J, Zhang Z, Miller W, Lipman D]: Gapped BLAST and PSI-BLAST: a new generation of protein database search programs. Nucleic Acids Res 1997, 25(I7):3389-3402.

67. Westphal O, Jann K: Bacterial lipopolysaccharides, extraction with phenol-water and further applications of the procedure. Methods CarbohydrChem I965, 5:83-9I.

68. Fischer W, Koch HU, Haas R: Improved preparation of lipoteichoic acids. Eur J Biochem 1983, I33(3):523-530.

69. Tellam RL, Eisemann CH, Vuocolo T, Casu R, Jarmey J, Bowles V, Pearson R: Role of oligosaccharides in the immune response of sheep vaccinated with Lucilia cuprina larval glycoprotein, peritrophin-95. Int J Parasitol 200I, 3 I (8):798-809.

70. Rothel JS, Corner LA, Lightowlers MW, Seow HF, McWaters P, Entrican G, Wood PR: Antibody and cytokine responses in efferent lymph following vaccination with different adjuvants. Vet Immunol Immunopathol 1998, 63(1-2): I67-I83.

71. Feng $W$, Zheng $X:$ Comparing techniques for detecting the number of somatic cells in raw milk. European Food Research and Technology 2005, 220(5-6):653-657.

72. Vuocolo T, Pearson R, Campbell P, Tellam RL: Differential expression of Dlk-I in bovine adipose tissue depots. Comp Biochem Physiol B Biochem Mol Biol 2003, I 34(2):3 I 5-333.

73. Loomis KH, Yaeger KW, Batenjany MM, Mehler MM, Grabski AC, Wong SC, Novy RE: InsectDirect System: rapid, high-level protein expression and purification from insect cells. J Struct Funct Genomics 2005, 6(2-3): 189-194.

74. Proctor RA, Mosher DF, Olbrantz PJ: Fibronectin binding to Staphylococcus aureus. J Biol Chem 1982, 257(24): | 4788- | 4794.
Publish with Bio Med Central and every scientist can read your work free of charge

"BioMed Central will be the most significant development for disseminating the results of biomedical research in our lifetime. "

Sir Paul Nurse, Cancer Research UK

Your research papers will be:

- available free of charge to the entire biomedical community

- peer reviewed and published immediately upon acceptance

- cited in PubMed and archived on PubMed Central

- yours - you keep the copyright
BioMedcentral 